\title{
Detecting the influence of fossil fuel and bio-fuel black carbon aerosols on near surface temperature changes
}

\author{
G. S. Jones, N. Christidis, and P. A. Stott \\ Met Office Hadley Centre, Exeter, UK \\ Received: 6 August 2010 - Published in Atmos. Chem. Phys. Discuss.: 2 September 2010 \\ Revised: 5 January 2011 - Accepted: 18 January 2011 - Published: 26 January 2011
}

\begin{abstract}
Past research has shown that the dominant influence on recent global climate changes is from anthropogenic greenhouse gas increases with implications for future increases in global temperatures. One mitigation proposal is to reduce black carbon aerosol emissions. How much warming can be offset by controlling black carbon is unclear, especially as its influence on past climate has not been previously unambiguously detected. In this study observations of near-surface warming over the last century are compared with simulations using a climate model, HadGEM1. In the simulations black carbon, from fossil fuel and biofuel sources (fBC), produces a positive radiative forcing of about $+0.25 \mathrm{Wm}^{-2}$ over the 20th century, compared with $+2.52 \mathrm{Wm}^{-2}$ for well mixed greenhouse gases. A simulated warming of global mean near-surface temperatures over the twentieth century from $\mathrm{fBC}$ of $0.14 \pm 0.1 \mathrm{~K}$ compares with $1.06 \pm 0.07 \mathrm{~K}$ from greenhouse gases, $-0.58 \pm 0.10 \mathrm{~K}$ from anthropogenic aerosols, ozone and land use changes and $0.09 \pm 0.09 \mathrm{~K}$ from natural influences. Using a detection and attribution methodology, the observed warming since 1900 has detectable influences from anthropogenic and natural factors. Fossil fuel and bio-fuel black carbon is found to have a detectable contribution to the warming over the last $50 \mathrm{yr}$ of the 20th century, although the results are sensitive to the period being examined as $\mathrm{ABC}$ is not detected for the later fifty year period ending in 2006. The attributed warming of $\mathrm{fBC}$ was found to be consistent with the warming from $\mathrm{fBC}$ unscaled by the detection analysis. This study suggests that there is a possible significant influence from $\mathrm{fBC}$ on global temperatures, but its influence is small compared to that from greenhouse gas emissions.
\end{abstract}

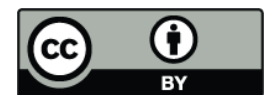

Correspondence to: G. S. Jones (gareth.s.jones@metoffice.gov.uk)

\section{Introduction}

Global near-surface temperatures have increased by over $0.7 \mathrm{~K}$ since the beginning of the 20th century (Brohan et al., 2006; Trenberth et al., 2007) with further warming projected to occur as a result of increasing concentrations of greenhouse gases (Meehl et al., 2007). It has been proposed that controlling future black carbon aerosol emissions may be an effective way of mitigating some of this future climate change and be easier to attain than reducing greenhouse gas emissions alone (Hansen et al., 2007; Boucher and Reddy, 2008; Shindell et al., 2008; Wallack and Ramanathan, 2009; Kopp and Mauzerall, 2010). Aerosols produced from the burning of fuels and vegetation are comprised mostly of sulphate and carbonaceous aerosols. The latter aerosol is made up of components from incomplete combustion, black carbon and complex carbon molecules called organic carbon or particulate organic matter (Forster et al., 2007). Whilst the overall influence of anthropogenic aerosols is one of cooling (Haywood and Schulz, 2007), the radiative influences of the different aerosol species are more complex with both scattering and absorbing properties. Black carbon is of particular interest as it is radiatively an absorbing aerosol so whilst it decreases the amount of incoming shortwave radiation (SW) reaching the surface, it can warm the atmosphere and surface through re-emitted longwave radiation (LW) and stabilisation of the lower atmosphere (Ramanathan et al., 2005). This causes complex warming and cooling patterns throughout the atmosphere. The main sources of black carbon aerosol (BC) are fossil fuels (e.g. diesel and coal), bio-fuels (e.g. domestic wood stoves) and biomass burning (agricultural waste burning and forest fires). Organic carbon aerosols (OC) are also produced from these sources, but in largest concentrations from biomass burning sources.

There is evidence that BC's contribution to so called atmospheric brown clouds over the Indian Ocean and Asia

Published by Copernicus Publications on behalf of the European Geosciences Union. 
may have as much warming influence in those regions as recent greenhouse gas increases (Ramanathan et al., 2007). Black carbon aerosol has also been associated with changes in South Asian monsoon activity (Meehl et al., 2008) and tropical convective precipitation (Wang, 2009) by changing troposphere temperature gradients, and may have considerable regional influence by changing the albedo of snow in the Arctic (Hansen and Nazarenko, 2004) and the Himalayas (Xu et al., 2009). Together with methane and tropospheric ozone, black carbon aerosols are amongst the next most important radiative warming influence after $\mathrm{CO}_{2}$ (Forster et al., 2007), but it is not clear how much of recent global climate change may have been influenced by the aerosol and consequently how much of an impact future controls of black carbon would have on climate change.

Anthropogenic and natural influences have been detected in recent changes in climate (IDAG, 2005) with the Intergovernmental Panel on Climate Change (IPCC, 2007) reporting that it was "very likely" (>90\%) that most of the warming over the last $50 \mathrm{yr}$ was caused by increases in anthropogenic greenhouse gases and that it was "likely" $(>66 \%)$ that the increase would have been larger than the observed warming if it were not for offsetting cooling from aerosols (anthropogenic and volcanic). A previous study (Jones et al., 2005b) used atmosphere-slab ocean coupled model simulations using sulphate aerosol and fossil fuel sources of black carbon (Roberts and Jones, 2004) to attempt to detect the two influences separately. However, the two simulated climate patterns were degenerate, so whilst it was possible to detect a greenhouse gas influence and a net total aerosol cooling influence, it was not possible to say how much was due to cooling from sulphate aerosols and how much of this was offset by warming from black carbon aerosols. The influence of carbonaceous aerosols (black carbon and organic carbon from a variety of sources) was detected in a different study (Nagashima et al., 2006), albeit in the mid part of the 20th century.

Here we examine how much influence fossil fuel and biofuel black carbon aerosol (fBC) has on recent climate change. We use the term $\mathrm{BBC}$ for fossil fuel and bio-fuel sources of $\mathrm{BC}$ to avoid confusion with the black carbon emissions from forest fire and agricultural waste burning that are included in biomass burning aerosol (BB) emissions. We use the Hadley Centre climate model, HadGEM1, to examine the radiative effects of changes in fBC over the last 100 or so years and by using a detection and attribution analysis methodology deduce what contribution to the recent warming could be from fBC. In Sect. 2 we describe the model, emissions and other external forcing agents used in the simulations. Section 3 describes the results of the simulations including estimates of the radiative forcings and the climate responses. Section 4 describes the detection and attribution methodology used to detect the climate changes and attribute their causes with the results of the analysis.

\section{Model description}

We use the Hadley Centre Global Environmental Model (HadGEM1), a coupled Atmosphere-Ocean General Circulation Model, with an atmosphere resolution of $1.25^{\circ}$ by $1.875^{\circ}$ and 38 layers and with an ocean resolution that varies between $1^{\circ}$ by $1^{\circ}$ to $0.33^{\circ}$ with 40 levels (see Stott et al. (2006a) and references therein for further details). A suite of simulations was run with different combinations of forcing factors. Between 3 and 4 simulations were completed for each of the different combinations of forcing factors initiated from different starting conditions based on the HadGEM1 control (HG1CTL), (Table 1). The anthropogenic forcing factors comprise changes in well mixed greenhouse gases $\left(\mathrm{CO}_{2}\right.$, $\mathrm{CH}_{4}, \mathrm{~N}_{2} \mathrm{O}$, CFCs and HCFCs), aerosols (sulphate, fossil fuel and bio-fuel black carbon, biomass burning), ozone (tropospheric and stratospheric) and land use (influencing surface processes as well as albedo). Natural forcings included are changes in volcanic stratospheric aerosols and solar irradiance (TSI). Full details of the forcing factors applied and how they are modelled are described in the works of Johns et al. (2006); Martin et al. (2006) and Stott et al. (2006a). The simulations were extended beyond 2000 by including anthropogenic emissions and concentrations used in the A1B SRES scenario simulation described in Stott et al. (2006a). For the natural forcings factors it was assumed that the stratospheric volcanic aerosol remaining in 2000 decayed with a timescale of $1 \mathrm{yr}$ (Sato et al., 1993), and that the TSI had an $11 \mathrm{yr}$ cycle with an amplitude calculated as the average of the previous two cycles.

By calculating the ensemble averages of the simulated data it is possible to obtain the best estimate of the signal pattern of whatever climate parameter is being examined. Looking at the differences between the different simulations averages the best estimates of the individual components can be estimated (Table 2), assuming linearity between the forcing factors (Stott et al., 2000; Gillett et al., 2004). The number of simulation ensembles available are extended from that originally reported in Stott et al. (2003a) and Jones et al. (2008).

How aerosols are incorporated into the model is described in Martin et al. (2006) and references therein. The black carbon aerosol emitted from fossil fuel and biofuel sources (fBC) is assumed to be purely black carbon in composition with radiative absorbing properties, with the emissions at height away from the surface. The biomass burning aerosols (BB) are assumed to have both absorbing and scattering radiative properties, containing black carbon and other materials such as organic carbon, to form a common aerosol (Jones et al., 2007). The BB aerosols are emitted from forest fires and agricultural waste burning, with the forest fire component emitted at height and the agricultural waste component emitted near the surface. Apart from $\mathrm{ABC}$, which in HadGEM1 have only direct and semi-direct effects, all the aerosols have direct, semi-direct and indirect effects (Martin et al., 2006). Changes in snow albedo due to lying black 
Table 1. Model simulations, all HadGEM1 unless otherwise stated. Period covered by transient simulations 1 December 185930 November 2007 (1860-2007), with some simulations extended to 2029 .

\begin{tabular}{lll}
\hline Name & Description & $\begin{array}{l}\text { Number of } \\
\text { ensemble } \\
\text { members }\end{array}$ \\
\hline GHG & Well mixed greenhouse gases (WMGHGs) & 3 \\
\hline ANTHRO & $\begin{array}{l}\text { Anthropogenic factors - WMGHGs; } \\
\text { Sulphate, fBC and BB aerosols; } \\
\text { O }_{3} \text { and land use changes }\end{array}$ & 4 \\
\hline ALL & $\begin{array}{l}\text { All anthropogenic and } \\
\text { natural forcing factors }\end{array}$ & 4 \\
\hline ALLnofBC & $\begin{array}{l}\text { Anthropogenic (except fBC) and } \\
\text { natural forcing factors }\end{array}$ & 3 \\
\hline HG1CTL & $\begin{array}{l}\text { Control simulation with no changes } \\
\text { in external forcings, 920 yr long }\end{array}$ & 1 \\
\hline HC3CTL & $\begin{array}{l}\text { HadCM3 control, 1150 yr long. } \\
\text { To be used as part of detection analysis }\end{array}$ \\
\hline
\end{tabular}

carbon (e.g. Hansen and Nazarenko, 2004) are not included in the model.

There have been a considerable number of studies investigating the impact of various aspects of aerosols on climate, demonstrating significant uncertainties (e.g. Koch et al., 2009a; Myhre, 2009), with the latest IPCC report given the level of scientific understanding for the direct radiative effect of aerosols to be "medium to low" and for the indirect radiative effect to be "low" (Forster et al., 2007). Investigations of $\mathrm{BC}$ and other carbonaceous aerosols processes and impacts has substantially grown over recent years (e.g. Koch et al., 2009b). Some analyses have been based on simple climate models without any aerosol processes (e.g. Andreae et al., 2005). Studies have also used satellite and ground based observations of radiative fluxes (Ramanathan and Carmichael, 2008) to deduce the radiative impacts. Others have included complex aerosol chemistry and processes (Chung and Seinfeld, 2005) with atmospheric climate models looking at equilibrium responses in the climate. Observations have also been compared with models to quantify the model's strengths and weaknesses (Bellouin et al., 2008; Myhre, 2009). Whilst these studies are very important in understanding the importance of the aerosol processes, for the purposes of examining the impact of different forcing factors changing over time on climate a balance needs to be found between the costs of producing climate simulations with the level of complexity of specific processes within the model (Pope et al., 2007). For instance it is important not to focus on the ability of the model to just simulate all aerosol processes, but rather on how well the most important aerosol and other atmospheric and oceanic processes together are simulated, as has also been demonstrated in other studies (e.g.
Table 2. Estimated individual forcing factor contributions that can be deduced, by linear combination of available simulations, as described in Table 1.

\begin{tabular}{|c|c|c|}
\hline Name & Calculated & Description \\
\hline $\mathrm{OA}$ & ANTHRO - GHG & $\begin{array}{l}\text { Other anthropogenic forcings } \\
\text { when WMGHGs are not included. }\end{array}$ \\
\hline $\begin{array}{l}\text { NATURAL } \\
\text { fBC }\end{array}$ & $\begin{array}{l}\text { ALL - ANTHRO } \\
\text { ALL - ALLnofBC }\end{array}$ & $\begin{array}{l}\text { Natural forcing contribution } \\
\text { fBC contribution }\end{array}$ \\
\hline
\end{tabular}

Hansen et al., 2005; Nagashima et al., 2006). In this context we view HadGEM1 as an appropriate model to use to investigate the impact of different forcing factors, including fBC aerosols, on near surface temperature changes over the last $50-100$ yr.

HadGEM1 includes advances in aerosol modelling over previous generations of Hadley Centre models (Jones et al., 2001; Woodage et al., 2003; Roberts and Jones, 2004). Uncertainties in emission datasets and model processes can lead to uncertainties in the spatial distribution of aerosols. For instance how fBC aerosols are vertically distributed (e.g. Fig. 9 in Martin et al., 2006) can impact on radiative and hydrological processes (Koch and Del Genio, 2010). HadGEM1 has been validated against observed climatology and variability (Martin et al., 2006; Ringer et al., 2006; Johns et al., 2006) which included meteorological parameters that are significantly influenced by aerosols, such as surface temperature distributions, cloud, precipitation, and radiative fluxes. Whilst there have been no direct comparisons of simulated aerosols within HadGEM1 and the limited available direct observations of individual aerosol species, a comparison of top of the atmosphere (TOA) fluxes produced from the model with observed satellite measurements (Bodas-Salcedo et al., 2008) show that the aerosol modelling impact on the surface radiation budget is credible. The aerosol radiative forcings estimates (Sect. 3.1) are consistent with values evaluated for a range of climate models in the IPCC assessment (Forster et al., 2007). When forced with anthropogenic and natural influences HadGEM1 was found to produce near-surface temperature variations consistent with observed 20th century temperatures changes (Stott et al., 2006b). The model has been included in many multi-model studies and of the models included in the IPCC climate assessment HadGEM1 is amongst the most sophisticated (Randall et al., 2007).

The forcing datasets used in the simulations are described in Stott et al. (2006a). The fBC and BB aerosol datasets were provided by T. Nozawa, personal communication, 2004, based on a variety of agricultural, emission and energy databases for the historic period and deduced from projected population, fuel usage and land use changes for the post 2000 period (see also Takemura et al., 2005 and discussion in Roeckner et al., 2006). The BB aerosol emissions were estimated by scaling the emissions of black carbon from 

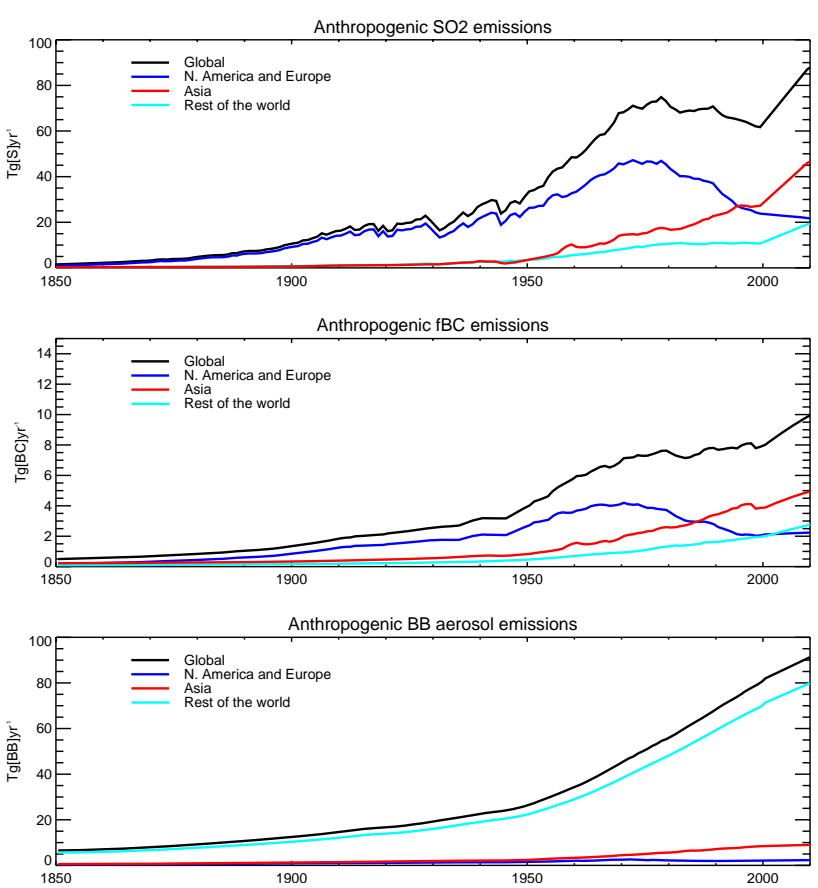

Fig. 1. Emissions of the major aerosol components used in the simulations (sulfur dioxide, black carbon from fossil and bio fuel sources and biomass burning aerosols). Details of the sources of the historic emissions between 1860 and 2000 and A1B SRES scenario emissions post 2000, can be found in the work of Stott et al. (2006a).

agricultural waste and forest fires by a factor of 10 and then treating them as a common aerosol containing $\mathrm{BC}$ and $\mathrm{OC}$, as it is assumed that the black carbon emissions from these sources (not fossil fuel and bio-fuel) comprise about $10 \%$ of the total mass of the BB aerosol emissions (A. Jones, personal communication, 2009). Figure 1 shows the time history of the emissions of sulfur dioxide and the $\mathrm{ABC}$ and $\mathrm{BB}$ aerosols used in the simulation. Changes in emissions over North America and Europe compared with Asia are shown, together with the remaining parts of the world. The evolution of fBC spatially and temporally have some similarities to the evolution of $\mathrm{SO}_{2}$ emissions, especially up to 1950 , but differ somewhat after that date due to changes in fuel sources. Global $\mathrm{fBC}$ emissions started to increase in the second half of the 20th century with emissions in North America and Europe peaking in 1970 being compensated by rapid increases across Asia and the rest of the world due to increased industrialisation (Fig. 2).

There are uncertainties in all the historic forcing factors but for aerosol these are particularly large. Not only are the evolution of total global emissions and concentrations uncertain but also how they change from region to region. The $\mathrm{SO}_{2}$ global emissions in the 1990s used in this study are at the lower limit of the range of estimates given by the most recent IPCC report (Forster et al., 2007). Alternatively
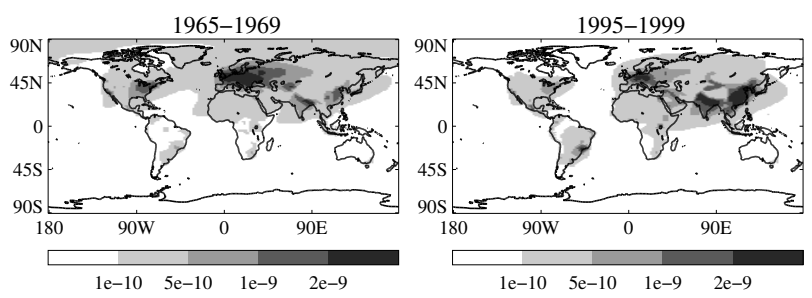

Fig. 2. Near-surface fBC concentrations (mmr) for the mean of the ALL simulations, for the two periods 1965-1969 and 1995-1999.

$\mathrm{fBC}$ emissions in 2000 used in this study totalled $8 \mathrm{Tg} \mathrm{y}^{-1}$ whilst other estimates vary between $5.6 \mathrm{Tg}^{-1}$ from only fossil-fuel sources (Novakov et al., 2003) to $4.4 \mathrm{Tg} \mathrm{y}^{-1}$ from fossil-fuel and biofuel sources (Bond et al., 2007) albeit with a range of 1.02 to $14.34 \mathrm{Tg}^{-1}$. The CMIP5 recommended BC dataset (Lamarque et al., 2010) is an updated version of the Bond et al. (2007) dataset and reports total anthropogenic emissions of $\mathrm{BC}$ to be $5.02 \mathrm{Tg}^{-1}$ in the year 2000 . Studies of aerosol intercomparison simulations (AeroCom) gave burdens of wild-fire, bio and fossil fuel sources of BC for the year 2000 of between 0.08 and $0.27 \mathrm{Tg}$ (Schulz et al., 2006) and BC lifetimes of 4.4 to 11.4 days. The equivalent $\mathrm{fBC}$ burden of HadGEM1 is $0.33 \mathrm{Tg}$ and a lifetime of the fBC aerosol of 15 days (Roberts and Jones, 2004) both of which are slightly outside the range of the AeroCom simulations, although the $\mathrm{BC}$ emissions in the AeroCom studies is somewhat lower $\left(6.32 \mathrm{Tg}^{-1}\right)$ than used in this study. Additional uncertainties are introduced due to the choice of post 2000 forcings factors. Whilst $\mathrm{CO}_{2}$ concentrations are close to what has been observed (Rahmstorf et al., 2007) other greenhouse gases, such as methane, have evolved differently (Forster et al., 2007). Measurements of clear-sky optical depth suggest a larger increase in recent aerosol emissions than reported in some studies (Wang et al., 2009), with the scale of increases in some regions (e.g. East Asia) varying from study to study (e.g. Ohara et al., 2007; Smith et al., 2010). Natural radiative forcings over the 20th century are relatively poorly understood, even during recent decades. There have been no major volcanic eruptions since the turn of the century (Thomason et al., 2008) supporting the choice made for post 2000 variations. However solar irradiance in 2008 may have been somewhat lower than the TSI used here, e.g. http://www.pmodwrc.ch/, as the Sun has entered a long period of solar minimum. Like the anthropogenic forcings, the uncertainties post 2000 are likely to be small compared to those during the century before.

It is outside the scope of this study to fully investigate the possible impact of the modelling and forcing uncertainties, although sensitivity of the detection results to the inclusion of post 2000 climate data is examined in Sect. 4. 


\section{Results}

In this section we describe the simulated near-surface temperature response but first we examine the radiative effects of the different forcing factors.

\subsection{Radiative effects}

Examining the different contributions to the radiative forcing is helpful in interpreting the climate changes simulated. A variant of the method of Gregory et al. (2004) is used to estimate the radiative forcing for the transient climate simulations. The method, detailed in Forster and Taylor (2006), takes the form of:

$N=Q-Y \Delta T_{\mathrm{S}}$

where $N$ is the net downward heat flux into the climate system measured at the top of the atmosphere (TOA), $Q$ is the radiative forcing, $Y$ is the climate feedback factor (also known as the climate feedback parameter, equivalent to the inverse of climate sensitivity parameter Forster et al. (2007) - the equilibrium change in temperature to a unit change in forcing) and $\Delta T_{\mathrm{S}}$ the change in global surface air temperatures. The TOA radiative fluxes and the surface air temperatures are obtained from the climate simulations. The SW and LW climate feedback factors were deduced from a $1 \% \mathrm{yr}^{-1} \mathrm{CO}_{2}$ HadGEM1 simulation by regressing $Q-N$ against $\Delta T_{\mathrm{S}}$, where $Q$ had been diagnosed (Forster and Taylor, 2006); $Y_{\mathrm{SW}}=-1.05 \mathrm{Wm}^{-2} \mathrm{~K}^{-1}$ and $Y_{\mathrm{LW}}=2.43 \mathrm{Wm}^{-2} \mathrm{~K}^{-1}$. We use these values, which are within the spread of the feedback parameters of the models included in the IPCC 4th assessment report (Randall et al., 2007), in our calculations.

There are a number of assumptions and issues to be considered whilst using this technique. It assumes that the climate feedback factors are the same for each of the forcing factors as for $\mathrm{CO}_{2}$, (the implications of this assumption are discussed below), and only incorporates those feedbacks that are proportional to surface air temperatures. It also assumes that the climate feedbacks do not change over the period being examined.

The estimated radiative forcings, $Q_{\mathrm{LW}}$ and $Q_{\mathrm{SW}}$ for the three simulations GHG, ANTHRO and ALL (Table 1) are shown in Fig. 3. The ensemble average of the simulations are shown together with their ten year running means. The technique produces values that have significant inter-annual variability for single simulations, so averaging and smoothing helps to deduce the actual changes in radiative forcing. The smoothing is useful for understanding the slowly changing forcings over multi-annual timescales, but is not as helpful in interpreting the rapidly changing forcings, such as from volcanic eruptions. The steady increase in LW forcing from increases in greenhouse gases is obvious in the figure. In the ANTHRO simulation this is partially offset by an increasing magnitude of negative SW forcing mostly from sulphate and
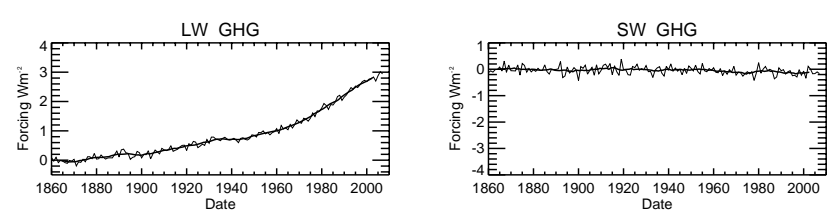

LW ANTHRO

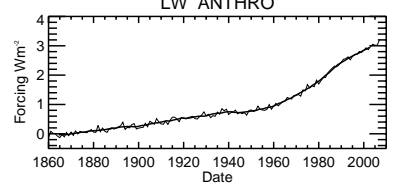

SW ANTHRO
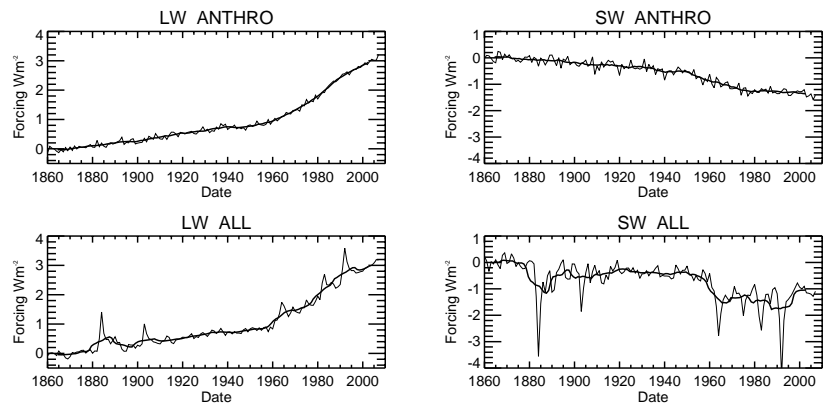

Fig. 3. Estimates of radiative forcing, longwave (LW) and shortwave (SW), for HadGEM1 simulations. Thin line - annual mean variations of the ensemble means, thick line $-10 \mathrm{yr}$ running mean of ensemble means.

biomass burning aerosols. A local minimum in 1980 is noticeable, when emissions of sulfur dioxide peaked in Europe and North America, but the SW forcing continues to decrease by 2000 associated with a projected increase in emissions from East and South Asia.

By looking at the differences of radiative forcings calculated from the available simulations, the individual contributions can be examined (Table 2). Figure 4 shows the radiative forcings for the non-greenhouse gas anthropogenic factors (OA), $\mathrm{fBC}$ and solar and volcanic factors (NATURAL). Because the estimates are based on differences between the previously described simulations, the forcing values on short timescales are more noisy but some time varying features are discernible. The OA comprises of LW and SW variations, due to the make up of sulphate aerosols, ozone, land use, biomass burning and $\mathrm{fBC}$ aerosol changes. The LW increase seen in OA is likely dominated by increases in tropospheric ozone, and the decrease in SW dominated by changes in aerosols. The LW warming and larger in magnitude SW cooling following volcanic eruptions (Jones et al., 2005a) is clear in the NATURAL, but an overall SW warming is also noticeable due to the increase in the TSI used in the simulation. The $\mathrm{fBC}$ forcing is dominated by changes in the SW which peak in the 1980s.

For the mean of the 1995-2004 period, GHG has a total $(\mathrm{SW}+\mathrm{LW})$ forcing of $+2.52 \pm 0.10 \mathrm{Wm}^{-2}$ and $\mathrm{OA}$ a forcing of $-1.04 \pm 0.13 \mathrm{Wm}^{-2}$. Uncertainties due to internal variability are estimated from the variations in $10 \mathrm{yr}$ means of the control simulation (HG1CTL) values of $N$ and $\Delta T_{\mathrm{S}}$, scaled to allow for the number of ensemble members and for any linear combinations for each forcing factor estimate. This compares favourably with the IPCC assessment of greenhouse gas forcing of $+2.63 \pm 0.26 \mathrm{Wm}^{-2}$ 

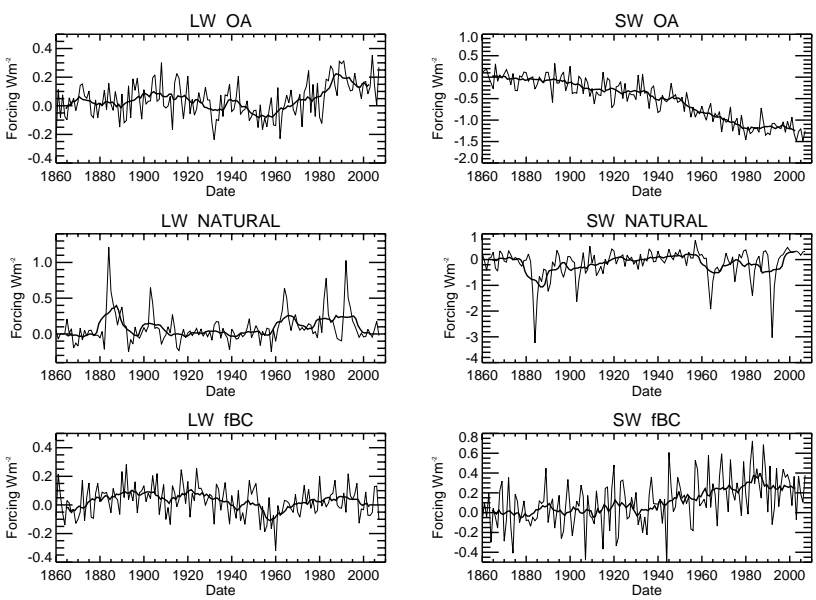

Fig. 4. Estimates of radiative forcing, LW and SW, for the individual HadGEM1 forcing components, deduced as differences between the forcing estimates shown in Fig. 3. Thin line - annual mean average, thick line $-10 \mathrm{yr}$ running mean.

and overall anthropogenic forcing of $+1.6(0.6$ to 2.4$) \mathrm{Wm}^{-2}$ (Forster et al., 2007), and the estimated aerosol forcing of $-1.06 \pm 0.4 \mathrm{Wm}^{-2}( \pm 1 \sigma)$ deduced from observations and energy balance calculations (Murphy et al., 2009). Natural influences are estimated to have a total forcing of $+0.30 \pm$ $0.10 \mathrm{Wm}^{-2}$, the long-term change being dominated by solar changes punctuated by short lived volcanic eruptions. The latest IPCC assessment is for a solar forcing of $+0.12(0.06$ to 0.30$) \mathrm{Wm}^{-2}$, reflecting the view that previous reconstructions used in climate studies, like the one used in the study, probably have had too much long term variation than currently thought (Forster et al., 2007). The forcing from fBC is estimated to be $+0.25 \pm 0.13 \mathrm{Wm}^{-2}$, similar in magnitude to the natural forcing, albeit with a different temporal evolution.

The climate forcing estimated assumes that the climate feedback factor has the same value for each of the forcing factors as for $\mathrm{CO}_{2}$, or in other words the forcing factors have efficacies of $\sim 1$ (Forster et al., 2007). This effective forcing can be thought of as being the "true" forcing scaled by the efficacy for that forcing agent (Forster and Taylor, 2006).

In previous studies it has been deduced that the efficacy for black carbon aerosol is less than 1 for Hadley Centre climate models. For HadSM4 the efficacy was estimated to be 0.62 (Roberts and Jones, 2004) with the same value calculated for HadGEM1 in a different study (Jones et al., 2007). If we use this efficacy with our estimate of the fBC effective forcing we obtain an estimated value of "true" forcing of $0.40 \pm 0.21 \mathrm{Wm}^{-2}$ which is consistent with the $0.45 \pm 0.01 \mathrm{Wm}^{-2}$ forcing deduced in the Jones et al. (2007) study. This "true" forcing, of BC from fossil fuel and biofuel sources, is at the upper end of the forcing estimates for fossil fuel only sources of BC deduced from a number of different sources (Table 2.5 in Forster et al., 2007) but is in the middle of the estimates of the forcing from both fossil fuel and biomass sources of $\mathrm{BC}$. The effective forcing may be a more useful parameter, however, as it demonstrates how much the climate is influenced by different factors without needing to consider what the climate sensitivity is for those factors.

The efficacy of black carbon aerosols has also been deduced to be less than 1 in a study based on a different model. For the GISS modelE, the response to black carbon emissions from fossil fuel sources only was estimated to have an efficacy of 0.78 (Hansen et al., 2005), with the effective forcing in 2000 estimated to be $+0.38 \pm 0.12 \mathrm{Wm}^{-2}$. Additionally the study also estimated the effect of this black carbon on snow via changing the albedo to have an effective forcing of $+0.17 \pm 0.10 \mathrm{Wm}^{-2}$ (with an associated efficacy of 1.7).

Diagnosed instantaneous forcings from the MIROC model (Takemura et al., 2006) gave a total aerosol (direct and indirect effects) forcing by 2000 of about $-1.1 \mathrm{Wm}^{-2}$, with sulphate, organic carbon and black carbon direct effect forcings estimated to be $-0.2,-0.3$ and $+0.4 \mathrm{Wm}^{-2}$ respectively (Takemura et al., 2005). The latest IPCC assessment (Forster et al., 2007) gave radiative forcings for present day with respect to 1750 for the direct effects of sulphate $(-0.4 \pm$ $\left.0.20 \mathrm{Wm}^{-2}\right)$, biomass burning $\left(+0.03 \pm 0.12 \mathrm{Wm}^{-2}\right)$, fossil fuel black carbon $\left(+0.2 \pm 0.15 \mathrm{Wm}^{-2}\right)$ and fossil fuel organic carbon $\left(-0.05 \pm 0.05 \mathrm{Wm}^{-2}\right)$ aerosols and a 1 st indirect effect forcing for all aerosols of $-0.7(-1.1$ to +0.4$) \mathrm{Wm}^{-2}$. It is suggested that these estimates have smaller uncertainties than the previous assessment (Haywood and Schulz, 2007). A study that combines satellite and surface observations with radiative flux models suggests that present day black carbon emissions from fossil fuel, biofuel and biomass burning sources may have an overall forcing of $+0.9(0.4$ to 1.2) $\mathrm{Wm}^{-2}$ (Ramanathan and Carmichael, 2008). A pseudo meta-analysis based on a selection of studies, including some mentioned above, concluded that the effective radiative forcing to contained combustion sources (fossil fuel and biofuel) of $\mathrm{BC}$ and $\mathrm{OC}$, including cloud and snow albedo effects was $+0.22 \mathrm{Wm}^{-2}$ (Kopp and Mauzerall, 2010). Not all studies suggest an overall warming influence from $\mathrm{BC}$ aerosols. One review (Koch and Del Genio, 2010) reports that some studies imply that the semi-direct effect of $\mathrm{BC}$ on clouds may offset the $\mathrm{BC}$ direct warming and a modelling study (Chen et al., 2010) suggests that reducing BC and OC from fossil fuel sources may produce an overall positive forcing by reducing the aerosol indirect effect.

\subsection{Near-surface temperature response}

The global annual mean near-surface $(1.5 \mathrm{~m})$ temperature response from the ALL simulation is shown compared to the observed temperatures, HadCRUT3v (Brohan et al., 2006) in Fig. 5, where the model has been re-gridded and sampled to match the observations data availability. This is an advance over the similar figure in Stott et al. (2003a) which only had one ensemble member of ALL which did not extend beyond 2000 and had a shorter length control available 


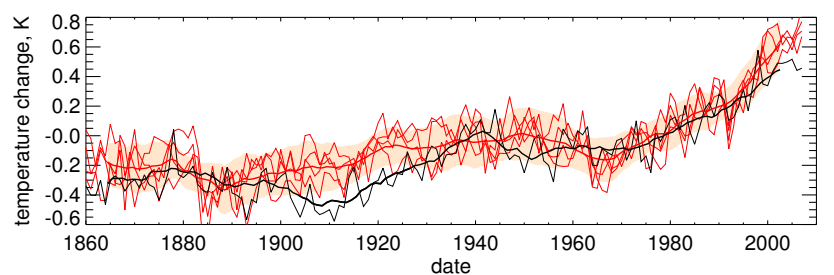

Fig. 5. Global mean near-surface temperature variations for the ALL simulated (red) and observed (HadCRUT3v) changes (black). The simulated data was regridded onto the observational grid and masked by the changing coverage of the observations. For the simulated data, anomalies were made with respect to the 1961-1990 mean as was done for HadCRUT3v. Thin lines- annual means for the observations and the four ALL ensemble members, thick lines 10 yr running mean allowing up to 9 missing years for observations and the average of the ALL ensemble. The shaded region represents an estimate of \pm 2 standard deviations, estimated from segments of HG1CTL, around the simulated $10 \mathrm{yr}$ running average of the ensemble mean.

for statistical analysis. The figure is qualitatively similar to Fig. 9.5 in Hegerl et al. (2007).

The HadCRUT3v trend between 1900 and 2007 was $+0.73 \pm 0.08 \mathrm{~K} /$ century, whilst the simulated trend was $+0.57 \pm 0.06 \mathrm{~K} /$ century (Table 3 ). Broad features of the observed 20th century are captured by the model, with some specific differences, possibly highlighted by the reference period used in the plot. Such differences, and conversely similarities, may be related to uncertainties in the forcings applied to the model, internal climate variability and uncertainties in the observations. HadCRUT3v slightly cools after the 1890 s to 1910 but subsequently warms to 1940 , whilst the simulation steadily warms over the same period. In both simulation and observations there is a lack of warming between the 1940s and 1970s followed by a subsequent warming to the present day. The ALL simulation warms between 1970 and 2007 by $+0.22 \pm 0.03 \mathrm{~K} /$ decade compared to the observed $+0.18 \pm 0.03 \mathrm{~K} /$ decade. The influence of the major volcanic eruptions are seen as short cooling episodes in both HadCRUT3v and the simulations (Jones et al., 2008). ENSO variability is not strongly simulated in HadGEM1 (Johns et al., 2006) but the random nature of such events would mean the model would not simulate the observed timing, e.g. the strong El-Nino event in 1998. Whilst the ElChichon eruption in 1982 caused cooling in the simulations there is no prominent cooling seen in the observations, due to one of the largest El-Nino events in the 20th century occurring at the same time. Strong warming was observed in the stratosphere following the El-Chichon eruption which was consistent with the simulations (Stott et al., 2006a). A coincident El-Nino is unlikely to be the explanation for the lack of cooling immediately following the Krakatau eruption in 1883 whose discrepancy with simulations is not fully understood (Joshi and Jones, 2009).
Table 3. Trends in global mean near-surface temperatures, $\mathrm{K} /$ century. The numbers in the second column represent the 19002007 trends in the global means of the simulated data processed as described in Fig. 7's caption. The third and fourth columns show the trends in the observed near-surface temperatures and the model simulations when the varying data coverage of HadCRUT3v is taken into account, as described in Fig. 5, for the 1900-2007 and 1958-2007 periods. The uncertainties ( \pm 2 standard deviations) are calculated from the errors in the least squares calculation for the observed trend and from the range of trends from segments taken from HG1CTL, scaled to allow for the number of members in each simulated ensemble.

\begin{tabular}{lr|rr}
\hline K/century & $\begin{array}{r}\text { Model data with } \\
\text { complete coverage }\end{array}$ & \multicolumn{2}{|c}{$\begin{array}{c}\text { Model sampled at same } \\
\text { locations as HadCRUT3v data }\end{array}$} \\
\hline & $1900-2007$ & $1900-2007$ & $1958-2007$ \\
\hline HadCRUT3v & & $+0.73 \pm 0.08$ & $1.27 \pm 0.23$ \\
\hline ALL & $+0.69 \pm 0.06$ & $+0.57 \pm 0.06$ & $1.76 \pm 0.18$ \\
ANTHRO & $+0.58 \pm 0.06$ & $+0.48 \pm 0.06$ & $1.63 \pm 0.18$ \\
GHG & $+1.14 \pm 0.07$ & $+1.06 \pm 0.07$ & $1.90 \pm 0.21$ \\
OA & $-0.56 \pm 0.09$ & $-0.58 \pm 0.10$ & $-0.26 \pm 0.27$ \\
NATURAL & $+0.10 \pm 0.08$ & $+0.09 \pm 0.09$ & $0.12 \pm 0.25$ \\
fBC & $+0.14 \pm 0.09$ & $+0.14 \pm 0.10$ & $0.31 \pm 0.27$ \\
\hline
\end{tabular}

Latitudinal changes with time in the near-surface temperatures are shown in Fig. 6. Again broad features are similar between the observed and simulated datasets. The warming over the early 20th century is global in nature for the ALL simulation, but HadCRUT3v is colder, mainly over the tropics for the first two decades and is significantly warmer in latitudes north of $65^{\circ} \mathrm{N}$ by 1940 . In contrast after the 1970s the warming in both datasets is more global in nature, although the model is warmer than the observations in the higher latitudes over the last $10 \mathrm{yr}$ of the record. HadCRUT3v is warmer in the mid 1960s perhaps due to the response to the Mt. Agung eruption in 1963 not cooling as much as is simulated.

We now turn to the individual contributions to the simulated climate change from the different forcing factors. The ensemble averages of GHG, OA, NATURAL and $\mathrm{ABC}$ are shown in Fig. 7. In this case the modelled data was not regridded and masked by the HadCRUT3v coverage in contrast to the data in Fig. 5, to more clearly examine regional changes by looking at all the available data. Between 1900 and 2007 , GHG warms by $+1.14 \pm 0.07 \mathrm{~K} /$ century and OA cools by $-0.56 \pm 0.09 \mathrm{~K} /$ century (Table 3 ), the uncertainties on these trends is the estimated variability of the ensemble mean, deduced from the HG1CTL variability. NATURAL over that period warms by $+0.11 \pm 0.08 \mathrm{~K} /$ century although the temporal variation is more complex than the other forcings. fBC warms by $+0.14 \pm 0.09 \mathrm{~K} /$ century, with much of the warming occurring over the last $50 \mathrm{yr}$ of the twentieth century $(+0.47 \pm 0.31 \mathrm{~K} /$ century). Thus the model simulation suggests that $\mathrm{ABC}$ has a similar, if not higher, rate 


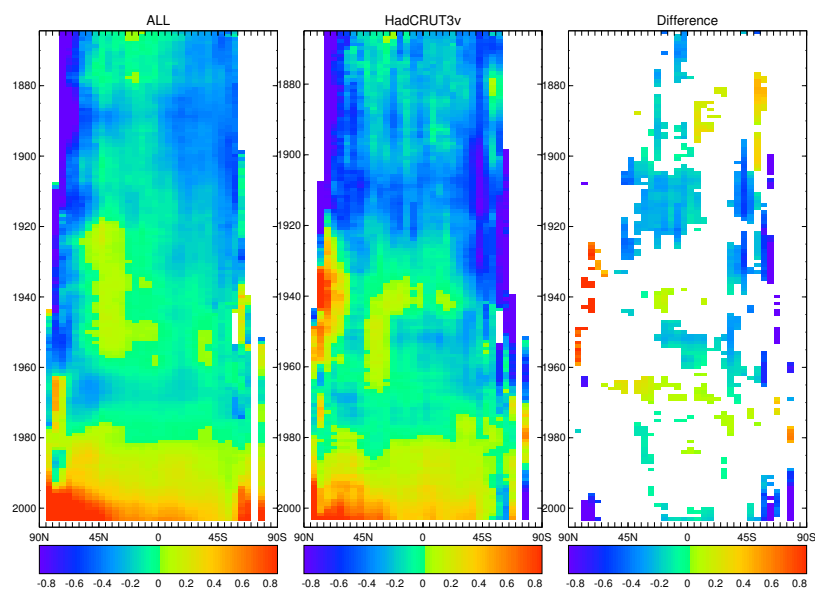

Fig. 6. Latitude/time plots of $10 \mathrm{yr}$ running mean near-surface temperature variations for the ensemble mean of the ALL simulation and observed changes. The data is processed as described in Fig. 5. The panel on the right hand side is the difference between HadCRUT3v and ALL showing only those differences that are significant ( \pm 2 standard deviations).

of warming over the 20th century as NATURAL. The temperature trends from these simulations when the data is regridded and masked by the observational data coverage are also given in Table 3. The influence of not fully sampling the globe's near surface temperature can be clearly seen in the trend for GHG. The strong high latitude warming simulated by climate models with increasing greenhouse gases is well known (Hegerl et al., 2007), and with poorer observational coverage in the Arctic the GHG trend is lower, $1.06 \pm 0.07 \mathrm{~K} /$ century.

The spatial patterns of climate change for the individual components are shown in Fig. 8. The cooling pattern of $\mathrm{OA}$ is concentrated in the Northern Hemisphere associated with the dominant aerosol emissions over Europe and North America and later South and East Asia (Roberts and Jones, 2004; Jones et al., 2007). Similarly fBC warms in similar areas to where OA cools but not with the same temporal evolution due to the aerosol species different regional emission histories (Fig. 1). The episodic cooling from the volcanic eruptions can clearly be seen in the NATURAL simulation. The steady warming during the early part of the 20th century is due to the increase in solar irradiance and the lack of volcanic eruptions in that period. Several years after the 1991 eruption of Pinatubo, NATURAL warms rapidly, not due to a rapid increase in solar irradiance which has little change in the period, but due to the recovery of the climate following the cooler period due to the 3 major eruptions of the previous $30 \mathrm{yr}$. Although volcanic eruptions have a dominant influence on climate over a few years after an eruption, there is a longer lived influence associated with heat changes in the ocean (Church et al., 2005; Gleckler et al., 2006) including possible change in the atlantic meridional overturning circu-

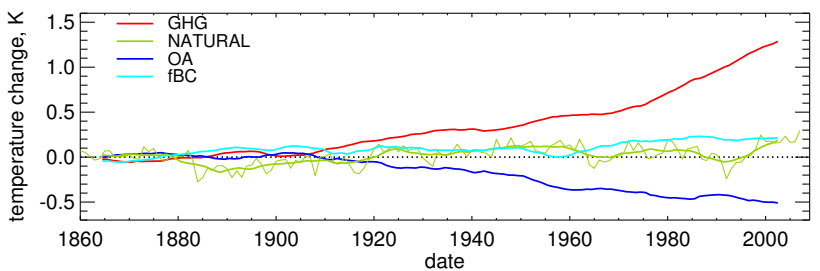

Fig. 7. $10 \mathrm{yr}$ running mean of near-surface temperature variations for the ensemble means of the GHG, OA, fBC and NATURAL simulated data. Anomalies were taken with respect to the first $50 \mathrm{yr}$ of the parallel control (HG1CTL) that each ensemble member were initialised from. Thin line is of annual means of the ensemble mean of NATURAL, to demonstrate the episodic cooling following the volcanic eruptions.

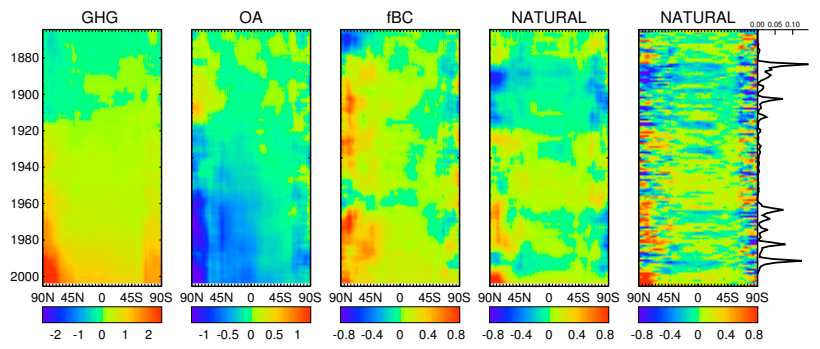

Fig. 8. The first four panels from the left are latitude/time plots of $10 \mathrm{yr}$ running mean near-surface temperature variations for the ensemble means of the GHG, OA, fBC and NATURAL simulated data. Processing of data as described for Fig. 7. The far right panel is the NATURAL latitude/time plot for annual mean data with global mean volcanic stratospheric optical depth also shown for comparison. The cooling periods, especially in the tropics, can be seen following the major volcanic eruptions.

lation (Jones et al., 2005a; Stenchikov et al., 2009) that may contribute to warming following periods of volcanic activity. The largest warming after the mid 1990s, in NATURAL, is seen north of $60^{\circ} \mathrm{N}$. A too large response to natural variations could partially explain the difference between ALL and the observed warming over the northerly high latitudes in this period (Fig. 6), but this region has high internal variability (Stott and Jones, 2009).

There have been claims that a lack of substantial warming seen in the $10 \mathrm{yr}$ since 1998 can be used to question the validity of climate simulations. Depending on the dataset looked at there is an apparent reduction in the rate of warming of near surface temperatures (Knight et al., 2009), but short periods of either little or increased warming are not unusual in the temperature record (Easterling and Wehner, 2009). A number of factors that could have contributed to temporary decreased rates of warming have been suggested, such as decreased solar activity (Lean and Rind, 2009), stratospheric water vapour variations (Solomon et al., 2010) or changes in how heat is distributed in the ocean (Smith et al., 2007). Decadal variations in atmospheric greenhouse gas 
concentrations, such as the reduction of the methane concentration growth rate (Forster et al., 2007) and a possible increase in global sulphate aerosols emissions since 2000 (Smith et al., 2010) could also be plausible significant contributing factors. However recent studies (Easterling and Wehner, 2009; Knight et al., 2009) support previously published views (Hegerl et al., 1996; Barnett et al., 1998) that periods of less than $20 \mathrm{yr}$ in length are too short to discriminate between internal climate variability and anthropogenic forced changes. The warming in HadCRUT3v between 2000 and 2007 is $0.11 \pm 0.16 \mathrm{~K} /$ decade, lower than the longer $30 \mathrm{yr}$ trend. Over the same period only two of the 4 ALL HadGEM1 simulations have significant positive trends and one actually cools by $-0.17 \pm 0.16 \mathrm{~K} /$ decade even though it has $30 \mathrm{yr}$ trend post 2000 of $0.25 \pm 0.05 \mathrm{~K} /$ decade. Together with whether it is possible to close the Earth's energy budget over the last few decades (Murphy et al., 2009; Trenberth and Fasullo, 2010) this suggests that there are difficulties in constraining long term climate change from short periods of observations. Because of this detection and attribution studies (IDAG, 2005; Stott et al., 2010) almost universally examine several or more decades of climate data variations.

\section{Detection analysis}

In this section we discuss the method and results of a detection and attribution analysis. We use the detection methodology of Allen and Stott (2003), a variate of methods (Hasselmann, 1997; Hegerl et al., 1996) that has been used in a wide range of studies on not only global near-surface temperature variations, but also regional temperatures, SSTs, temperatures aloft, precipitation, salinity and surface pressure (e.g. IDAG, 2005; Stott et al., 2010). We follow the details of optimal detection as laid out in Stott et al. (2003a) and Jones et al. (2008) and we recommend the reader to follow these descriptions for more details. The basic method is of a regression of simulated pattern climate responses for different forcings against the observed climate changes. Scaling factors of the simulated patterns give a measure of whether a particular forcing factor is detected, by testing the nullhypothesis that the scaling factors are consistent with a value of zero, i.e. a detection occurs when the scaling factor uncertainty range does not cross zero. The analysis is optimised by projecting the data onto an estimate of the empirical orthogonal functions (EOF), produced from the model control (HG1CTL), that represent the internal orthogonal modes of variability inherent in climate. The projections are weighted so that those modes with high signal to noise ratios (SNR) have more prominence than those with low SNR. The resulting regression is done with a method called total least squares (TLS) and a set of scaling factors, with a dependency on the number of EOFs used (or truncation), are produced following Eq. (2).
$y-v_{0}=\sum_{i=1}^{I} \beta_{i}\left(x_{i}-v_{i}\right)$

In Eq. (2) $y$ is the observed property and $x_{i}$ the simulated property for the $i$ th signal; $\beta_{i}$ is the scaling factors for the $i$ th signal; $v_{0}$ and $v_{i}$ are estimates of the noise in the observations and the simulations. The consistency of the results to over/under fitting is examined by comparing the residual of the regression with the expected variance as estimated from an independent control (HC3CTL) using an F-test (Tett et al., 2002). For multiple regression, to obtain the scaling factors for individual factors that were not directly simulated, a transformation is made. For example in the 2-way regression of ALL and ALLnofBC we can obtain the scaling factors for $\mathrm{fBC}$ and non $\mathrm{fBC}$ factors by a linear transformation (following Tett et al., 2002). To attempt to avoid confusion with terms used to describe the simulations (Tables 1 and 2) we use the terms G, A, N and B (Greenhouse gases, Anthropogenic, Natural and fBC respectively) to describe the scaling factors and responses deduced from the detection and attribution results. For instance " $\mathrm{A}+\mathrm{N}$ " refers to results for the anthropogenic plus natural signal whilst " $\mathrm{N}$ " refers to results for the natural signal only.

The same method was applied previously to an analysis comparing atmosphere-slab ocean models with the observed change in near-surface temperatures over the 20th century (Jones et al., 2005b). In that study the spatial pattern of the climate response were taken from simulations (using the HadSM3/4 models) containing a doubling of $\mathrm{CO}_{2}$, sulfur emissions and fossil fuel BC emissions in 1980. Of the observed $0.67 \mathrm{~K}$ warming, between 1895 and 1995, the results signified that $\mathrm{CO}_{2}$ was detectable, with a warming of just over $1 \mathrm{~K}$. The cooling effect of sulphate aerosols was degenerate with the warming effect of the fossil fuel $\mathrm{BC}$ so that the patterns were indistinguishable in the detection study. Thus the overall aerosol cooling was attributed to be about $-0.3 \mathrm{~K}$ but the contributions from fossil fuel $\mathrm{BC}$ and sulphate were not distinguishable. The historic aerosol emissions used in that study (Roberts and Jones, 2004) are different to that used in this study. A separate study (Nagashima et al., 2006) used the same detection methodology, applied to observed temperature changes over the 1940-1979 period and simulated temperatures from an atmosphere-ocean coupled model (MIROC). The study suggested that carbonaceous aerosols emissions (equivalent to $\mathrm{FBC}$ and $\mathrm{BB}$ aerosols in this study) contributed to that period of climate change. However that study did not detect black carbon's separate contribution.

Here we apply an optimal detection methodology to nearsurface $(1.5 \mathrm{~m})$ temperatures on two periods of lengths, $100 \mathrm{yr}$ and $50 \mathrm{yr}$. In all cases we process the data by taking $10 \mathrm{yr}$ means. For the calculation of the $10 \mathrm{yr}$ means any gridpoint with $5 \mathrm{yr}$ out of 10 or less of data is set to a missing data value. The simulated $10 \mathrm{yr}$ means are gridded onto the HadCRUT3v latitude/longitude grid and masked by its available coverage. This was repeated for overlapping segments for 
the controls, HG1CTL and HC3CTL, to be used for creating the eigenvector space and for statistical testing respectively. Each $10 \mathrm{yr}$ mean was then projected onto spherical harmonics (T4 truncation). All the data were then projected onto the EOFs (calculated from HG1CTL) and truncated by the maximum number of degrees of freedom (Allen and Stott, 2003). Model and observed periods covered 1/12/[Year] to $30 / 11 /[$ Year +10$]$ periods, so from herein such periods are called [Year + 1]-[Year + 10], e.g. for the 1 December 189930 November 1909 period it is described as 1900-1909.

\subsection{0 year analysis}

One issue that can have an influence on comparing results from different studies is aliasing. This is the effect of higher frequency variability appearing as lower frequency variability when filtered and discretely sampled (Press et al., 1992). Here and in other studies the use of $10 \mathrm{yr}$ means can cause the periodicities $<10 \mathrm{yr}$ to appear as a much lower frequency. This can potentially have the consequence of producing quite different detection results for the same data but covering slightly different periods. Because of the design of the detection methodology used here it is not possible to entirely avoid this problem. Due to this issue, and the questionable validity of using the A1B emissions post 2000 (as discussed in Sect. 2), we examine two periods 1900-1999 (as used in a variety of analyses: Tett et al. (2002) and Stott et al. (2006b)) and 1907-2006 (as used by Jones et al. (2008)) to explore the sensitivity of the results to the precise choice of period. The maximum number of EOFs allowed is 15 , i.e. truncation $=15$. In projecting the data onto the eigenvectors, if not enough EOFs are present then some important modes of variability may not be mapped into the eigenvector space. For the 1900-1999 and 1907-2006 periods $80 \%$ of the observed variability is captured by the projection (calculated following the method in Tett et al., 2002). This may influence the detection results if any rejected modes would otherwise contribute to the detection, and on the reconstruction of the attributed contributions (Sect. 4.3).

The simplest analysis is for a regression including only the ALL simulation. In both periods $\mathrm{A}+\mathrm{N}$ is detected robustly across the range of truncations, with scaling factors near and consistent with 1 (Fig. 9). The separate influences of anthropogenic (A) and natural $(\mathrm{N})$ influences are detected when regressed together (Table 4) for both the 1900-1999 and the 1907-2006 periods. In both cases the detections are robust to the choice of most of the truncations of EOF (Fig. 9). The consistency test, for the residuals of the regression to have the same statistical properties as an estimate of the internal variability, are passed for the maximum truncation. This indicates that there is no under or over fitting. For most of the lower truncations of EOF for the 1907-2006 period, however, the consistency test fails for $\mathrm{A}+\mathrm{N}$, indicating the residual of the regression has a significantly different variability than a measure of internal variability for those EOFs. Thus
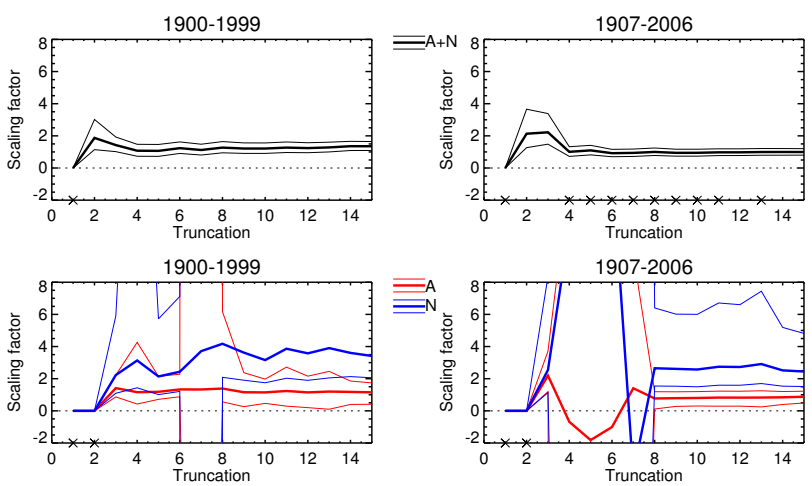

Fig. 9. $100 \mathrm{yr}$ analysis: scaling factors for the $\mathrm{A}+\mathrm{N}$ regression and the $\mathrm{A}$ and $\mathrm{N}$ multiple regression, showing sensitivity to choice of truncation, up to a maximum of 15 for the two periods, 1900-1999 and 1907-2006. Best estimate (Thick line) and 5-95\% range (thin lines). Where the residual of the regression fails a consistency test (where the F-test $p$ value falls outside 5-95\%) is marked on the axis with a "x".

whilst $\mathrm{A}+\mathrm{N}$ are detected for the 1907-2006 period, the failure of the consistency test for the range of EOF truncations reduces our confidence that this particular result is meaningful. Whilst A is detected consistent with a scaling factor of 1 , $\mathrm{N}$ has larger scalings. This could mean that the model is less responsive to natural forcings than in reality, that the forcing factors included in the model are not large enough in magnitude or the analysis technique is inaccurate. A similar result was also seen in a study that explored the possibility that solar influences were being underestimated by climate models (Stott et al., 2003b). In this case it appears the regression is attempting to fit the small warming seen in HadGEM1, caused by TSI increases and the lack of volcanic activity during the first half of the 20th century to the larger observed warming (see Sect. 4.3). Due to the way that the natural signal is estimated (i.e. the difference between ANTHRO and ALL) the signal will have a lower signal to noise ratio than is ideal. The estimated SNRs (method described in Tett et al. (2002)) for the A and $N$ signals respectively in the 1900 1999 period is $\mathrm{SNR}_{\mathrm{A}}=4.36$ and for $\mathrm{SNR}_{\mathrm{N}}=1.88$. These results, and those for other periods not shown, give consistent detection results for $100 \mathrm{yr}$ periods for each of the start years between 1899 and 1908. This suggests that aliasing and uncertainty in post 2000 forcing issues are not a major factor for the signals investigated.

When multiple regressions including $\mathrm{B}$ are examined none of the signals are detected. For instance for the $A+N-B$ and B analysis neither signals are detected. For the 19001999 period, $\mathrm{SNR}_{\mathrm{B}}=1.69$, which is a weak signal to be detected. A possible reason is if two, noise-free, signals are very similar, then the scaling factors can cover a wide range of possible values due to the degeneracy between them. In this case the two original signals being regressed $A+N$ and 
Table 4. Optimal detection results. Scaling factors for the 100 year and $50 \mathrm{yr}$ analyses, as shown in Figs. 9 and 10, for a truncation of EOF space of 15 . Results are given as best estimate together with $5-95 \%$ ranges. (* - Result marginally fails to pass the residual test for consistency, with a p value of 0.04.)

\begin{tabular}{lll}
\hline Signals & $1900-1999$ & $1907-2006$ \\
\hline $\mathrm{A}+\mathrm{N}$ & $1.35(1.09-1.64)$ & $0.99(0.80-1.20)$ \\
\hline $\mathrm{A}$ & $1.15(0.41-1.74)$ & $0.87(0.49-1.22)$ \\
$\mathrm{N}$ & $3.41(2.05-8.72)$ & $2.44(1.51-4.81)$ \\
\hline & $1950-1999$ & $1957-2006$ \\
\hline $\mathrm{A}+\mathrm{N}$ & $0.90(0.66-1.16)$ & $0.91(0.76-1.06)$ \\
\hline $\mathrm{A}$ & $0.73(0.46-0.99)$ & $0.80(0.57-1.00)$ \\
$\mathrm{N}$ & $-0.01(-0.85-0.66)$ & $0.95(0.37-1.73)$ \\
\hline $\mathrm{A}+\mathrm{N}-\mathrm{B}$ & $0.66(0.29-1.01)$ & $0.90(0.71-1.09)$ \\
$\mathrm{B}$ & $0.91(0.46-1.50)$ & $0.38(-0.15-0.87)$ \\
\hline $\mathrm{A}-\mathrm{B}$ & $0.61(0.26-0.93)$ & $0.92(0.70-1.15)$ \\
$\mathrm{N}$ & $-0.20(-1.07-0.48)$ & $0.80(0.19-1.43)$ \\
$\mathrm{B}$ & $0.95(0.50-1.47)$ & $0.38(-0.12-0.84)$ \\
\hline
\end{tabular}

$\mathrm{A}+\mathrm{N}-\mathrm{B}$ are similar in this analysis. Subsequently B, estimated from the transformation of the signals, has a low SNR and both $\mathrm{A}+\mathrm{N}-\mathrm{B}$ and $\mathrm{B}$ are not detected.

\subsection{0 year analysis}

As for the $100 \mathrm{yr}$ analysis we investigate the effect of looking at different periods by examining the 1950-1999 and 1957-2006 periods. The maximum allowable truncation is 26 , however for many of the signal combinations examined the residual test fails for the higher end of truncations, so to maintain a level of consistency throughout the following results we use a truncation of 15 . The scaling factors are not substantially different for truncation at 26 (Fig. 10). For the 1950-1999 and 1957-2006 periods some $81 \%$ and 84\%, respectively, of the observed variability is captured by the projection onto the eigenvectors.

We first investigate whether we can detect the influence of anthropogenic and natural forcings. Similarly to the $100 \mathrm{yr}$ analyses the simplest regression $(\mathrm{A}+\mathrm{N})$ gives robust detections (not shown) over the range of truncations, with narrow ranges consistent with a scaling value of 1 (Table 4). For the two way regression of $\mathrm{A}$ and $\mathrm{N}$ both are detected for the 1957-2006 period (Fig. 10 and Table 4) but only A is detected for the 1950-1999 period. The SNR is higher for both signals for the later period $\left(\mathrm{SNR}_{\mathrm{A}}=5.26\right.$ and $\left.\mathrm{SNR}_{\mathrm{N}}=1.98\right)$ than for the earlier period $\left(\mathrm{SNR}_{\mathrm{A}}=4.29\right.$ and $\left.\mathrm{SNR}_{\mathrm{N}}=1.81\right)$ which may partially explain the difference in the detection results. Alternatively there may be an aliasing influence where any differences between the climate response in the model and that observed are emphasised when the data is sampled,
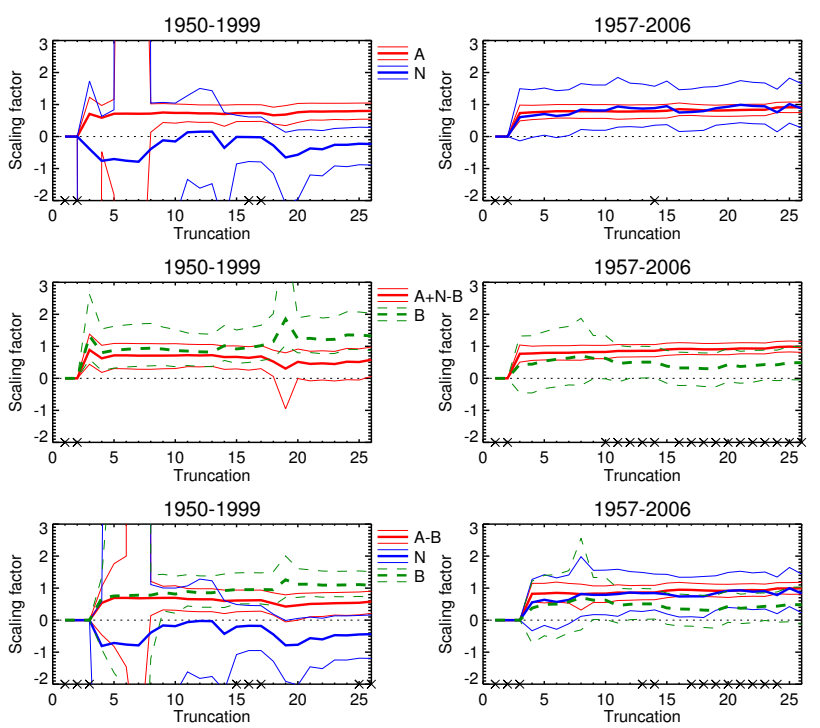

Fig. 10. $50 \mathrm{yr}$ analysis: scaling factors for the multiple regression analyses of $\mathrm{A}$ and $\mathrm{N} ; \mathrm{A}+\mathrm{N}-\mathrm{B}$ and $\mathrm{B} ; \mathrm{A}-\mathrm{B}, \mathrm{N}$ and $\mathrm{B}$ showing sensitivity to choice of truncation, up to a maximum of 15 for the two periods, 1900-1999 and 1907-2006. Best estimate (Thick line) and $5-95 \%$ range (thin lines). Where the residual of the regression fails a consistency test is marked on the axis with a " $x$ ".

for instance the signal of climate change from $\mathrm{N}$ will look different depending on what volcanic cooling events are sampled by the processing to create $10 \mathrm{yr}$ means. Sensitivity of detection results to choice of period has been seen in other studies (e.g. Tett et al., 2002).

We now go on to investigate whether we can detect B in the $50 \mathrm{yr}$ periods (Fig. 10 and Table 4). For the two way regression of $\mathrm{A}+\mathrm{N}-\mathrm{B}$ and $\mathrm{B}$ both are detected for the 19501999 period, although $\mathrm{A}+\mathrm{N}-\mathrm{B}$ is not detected for truncations above 18 . In the 3 way regression the A-B signal and $\mathrm{B}$ signal are detected but $\mathrm{N}$ is not. For the later 1957-2006 period, $\mathrm{B}$ is not detected in either the two way or three way regressions. $\mathrm{A}+\mathrm{N}-\mathrm{B}$ is detected and so are $\mathrm{A}-\mathrm{B}$ and $\mathrm{N}$. Where detected the scaling factors were largely consistent with 1 . The SNRs of the signals reflect the robustness of the detection of A-B and the more sensitive detections of $\mathrm{N}$ and $\mathrm{B}$; for $1950-1999 \mathrm{SNR}_{\mathrm{A}-\mathrm{B}}=4.02, \mathrm{SNR}_{\mathrm{N}}=1.81$ and $\mathrm{SNR}_{\mathrm{B}}=1.99$; and for $1957-2006 \mathrm{SNR}_{\mathrm{A}-\mathrm{B}}=4.69, \mathrm{SNR}_{\mathrm{N}}=$ 1.98 and $\mathrm{SNR}_{\mathrm{B}}=1.94$. The sensitivity of these results to the choice of period may suggest some influence from either the aliasing effect and/or uncertainties in the climate response to the not well understood forcings. Whilst B has higher SNRs for the $50 \mathrm{yr}$ analysis than for the $100 \mathrm{yr}$ period analysis, the values are not as high as for the other anthropogenic forcings. This will contribute a lower constraint on the uncertainties in the scaling factors (Allen and Stott, 2003). One issue we are unable to explore because of the design of our climate model experiments is the influence of the uncertainty of the relative 

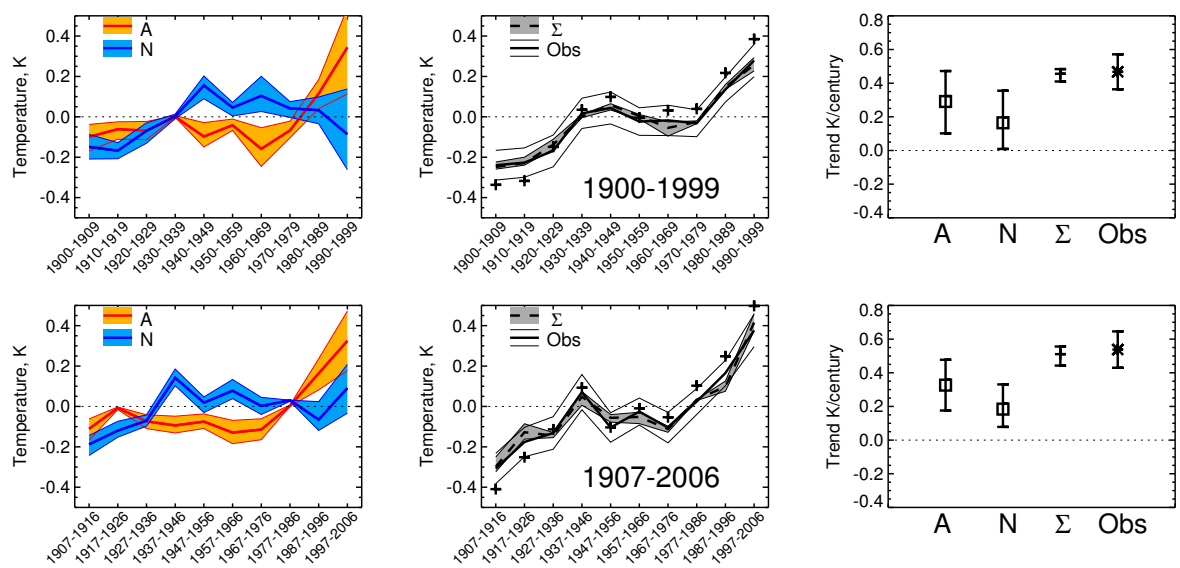

Fig. 11. Temperature reconstructions for $100 \mathrm{yr}$ analyses examining the A and $\mathrm{N}$ multiple regression compared with the HadCRUT3v variations (Obs). Top - results for 1900-1999 and bottom - 1907-2006 periods. LHS - decadal global means of reconstruction of A and N with the shaded regions representing the 5-95\% ranges. Middle - the shaded region and dashed line represent the best estimate of the sum of the $\mathrm{A}$ and $\mathrm{N}$ components $(\Sigma)$. The solid line thick and thin lines are the best estimate of the reconstructed observations and uncertainty range estimated from the HC3CTL. The crosses are the un-filtered/un-projected HadCRUT3v $10 \mathrm{yr}$ global mean values. RHS - Centennial trends of the reconstructions with $5-95 \%$ uncertainties.

contributions to the climate response from other non greenhouse gas anthropogenic forcing factors, specifically from the sulphate and biomass burning aerosols (Bellouin et al., 2007; Jones et al., 2007).

\subsection{Temperature reconstructions}

From the detection results it is possible to reconstruct the attributed contributions to the observed change. The data projected into the EOF space $\left(x_{i}\right)$ are scaled by the regression factors and then projected back into the original spherical harmonic space to construct best estimates and 5-95\% ranges of attributed global mean temperature changes (Allen and Stott, 2003). As stated earlier some of the variability may be lost during the projection onto the EOFs and then truncation. This becomes evident when the original global mean is compared with the filtered data, and so should be remembered when comparing the attributed climate changes with the original observed changes.

We first examine the reconstructions of the $100 \mathrm{yr}$ analysis to study the anthropogenic and natural contributions to the long term climate change. Figure 11 gives the reconstructed global mean near-surface temperatures The filtered observed global temperatures warmed by $0.46(0.36-$ $0.57) \mathrm{K}$ and $0.53(0.42-0.64) \mathrm{K}$ for the 1900-1999 and 19072006 periods respectively. The anthropogenic component, A, was attributed to have warmed by $0.29(0.10-0.47) \mathrm{K}$ and $0.32(0.17-0.47) \mathrm{K}$ for the two periods respectively with most of the warming occurring after around 1970. Additionally the natural component warmed by $0.16(0.0-0.35) \mathrm{K}$ and $0.18(0.07-0.33) \mathrm{K}$ for the two periods, with most of the warming occurring before the 1950s with a slight cooling afterwards. The sum of the scaled $\mathrm{A}$ and $\mathrm{N}$ components $(\Sigma$ in
Fig. 11) reconstruction matches the variations in the global mean of the filtered HadCRUT3v very well in both periods.

We now examine the reconstructions of the $50 \mathrm{yr}$ analysis including the analysis of the $\mathrm{fBC}$ contributions. For the signal combinations considered the scaled totals match the global means very closely. In all the analyses natural influences do not contribute significantly to the $50 \mathrm{yr}$ trend (Fig. 14) even though $\mathrm{N}$ is detected in the 1957-2006 period. The global mean of the filtered HadCRUT3v warms by $0.78(0.47-1.08) \mathrm{K} /$ century and $1.11(0.81-1.42) \mathrm{K} /$ century for the 1950-1999 and 1957-2006 periods respectively (which is slightly smaller than the unfiltered trends (Fig. 5, Sect. 3.2) due to the loss of variability in the analysis process). The total anthropogenic contribution is attributed to have warmed the periods by $0.73(0.48-0.96)$ and $1.16(0.81-$ $1.44) \mathrm{K} /$ century respectively (Fig. 14), suggesting that most of the trend in observed temperatures over the last $50 \mathrm{yr}$ is anthropogenic in origin (consistent with the conclusions of IPCC, 2007). The attributed climate change due to $\mathrm{fBC}$ differs between the two periods, with $\mathrm{B}$ being detected in the earlier period but not the latter. For the 1950-1999 period, in the two way regression $(\mathrm{A}+\mathrm{N}-\mathrm{B}$ and $\mathrm{B})$ the $\mathrm{B}$ component is attributed to warm by $0.41(0.20-0.60) \mathrm{K} /$ century and for the three way regression (A-B, N and B) by $0.40(0.20$ $0.55) \mathrm{K} /$ century. This is slightly larger than the other anthropogenic attributed warming of $0.35(0.14-0.52) \mathrm{K} /$ century. Alternatively for the 1957-2006 period, for the 3 way regression, $\mathrm{B}$ has a much smaller (non-significant) warming of $0.10(-0.03-0.21) \mathrm{K} /$ century, whilst the remaining anthropogenic forcings are attributed to warm by $1.06(0.81-$ 1.24) K/century. The reconstruction of the time varying global mean temperatures (Figs. 12 and 13) shows that the observations show little warming for 2-3 decades then a large 
increase after around 1970. The cooling of the decade containing the 1991 eruption of Mt. Pinatubo eruption is clear in the reconstructions of $\mathrm{N}$ for the 1957-2006 period but not the 1950-1999 period as $\mathrm{N}$ is only detected in the later period.

The sensitivity of these results to the choice of period is intriguing, and as discussed earlier may be due to B having a slightly lower SNR in the later period, uncertainty in the simulated temperature response due to the lack of accuracy of the variations of the forcings in the periods or an artifact of aliasing. Similar sensitivity of results, for different forcing factors, to choice of periods has been noted previously (Tett et al., 2002). The result from the 19501999 period suggests a contribution from $\mathrm{fBC}$ that may be larger than all the other anthropogenic forcings combined. Whilst this may seem at first to be an odd result, the sulphate and BB aerosol cooling influence will be larger in magnitude without $\mathrm{ABC}$ and thus offsets more of the greenhouse gas warming than if $\mathrm{fBC}$ was included. Figure 14 shows the temperature trends of the unscaled G, N, B and A-G-B, i.e. the anthropogenic response due to sulphate and biomass aerosols, ozone and land use change. The unscaled $\mathrm{B}$ response is very similar to the attributed warming from B deduced from the regression of the 1950-1999 period. The smaller A-B attributed warming can be seen to be consistent with $\mathrm{G}$ warming by about $1.3 \mathrm{~K} /$ century partially offset by A-B-G by about $-0.77 \mathrm{~K} /$ century. In line with the differing SNR values for B in the two periods, the unscaled B temperature response (Fig. 14$)$ is larger $(\sim 0.42 \mathrm{~K} /$ century) in the earlier period than in the later period $(\sim 0.27 \mathrm{~K} /$ century $)$. Although B is not detected, the attributed warming for B during 1957-2006 is consistent with its unscaled response. This suggests that the differing detection results for B may be due to it having a larger influence in the earlier period. The differences in the evolution of the attributed reconstructions shows that B warms up to the 1980s whilst the other anthropogenic forcings have a large warming in the decades after the 1970s. These results suggest that there is a potential important contribution to global warming during the 20th century from $\mathrm{fBC}$.

\section{Discussion}

Like similar detection and attribution analyses this study has a number of limitations. As has already been discussed there are large uncertainties regarding aerosol impacts on climate. Whilst there have been advances in the areas of modelling and observations of aerosols the radiative impact is still considerably less understood than greenhouse gas forcings (Haywood and Schulz, 2007). This study is unable to investigate the impact of aerosol emission and modelling uncertainties. As long as the patterns of warming and cooling are not significantly different, detection and attribution analyses can allow for uncertainties in the magnitude in the forcing or the climate response. One factor that isn't accounted for in this
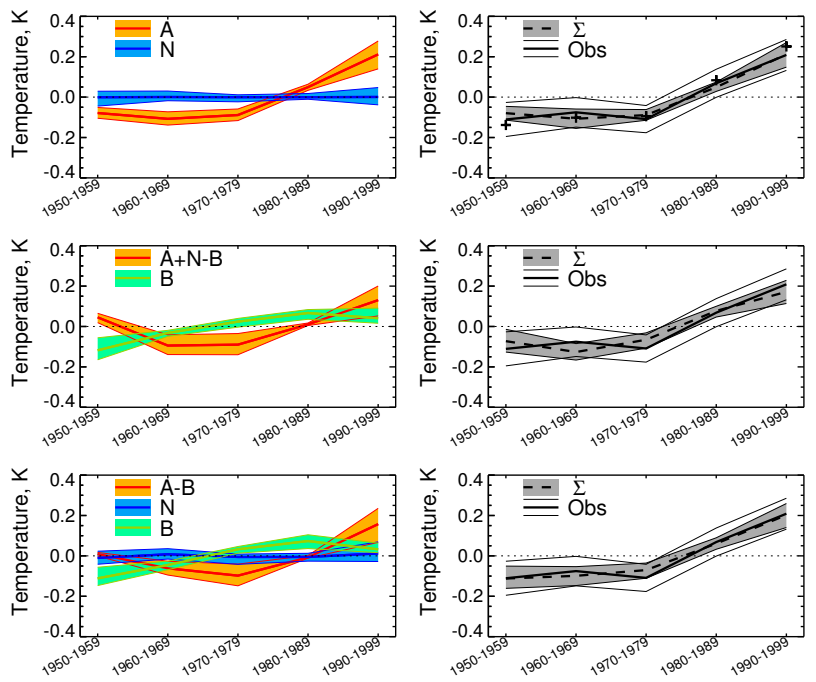

Fig. 12. Temperature reconstructions for the 1950-1999 period, truncation $=15$ compared with the HadCRUT3v variations (Obs). LHS - decadal global means of the reconstructed temperatures with the shaded regions representing the 5-95\% ranges. RHS- the shaded region and dashed line represent the best estimate of the sum of the individual component temperature reconstructions $(\Sigma)$. The solid line thick and thin lines are the best estimate of the reconstructed observations and uncertainty range estimated from the HC3CTL. The crosses are the un-filtered/un-projected HadCRUT3v 10 yr global mean values.

analysis is albedo changes due to BC deposition on snow, which is discussed further in this section. Previous studies examining different models have constrained the amount of greenhouse warming despite uncertainties between the aerosol modelling (Stott et al., 2006b), supporting our use of available model results for inclusion in this study. Development of future generations of Hadley Centre models is continuing, including increasing sophistication of aerosol modelling (Jones et al., 2007; Bellouin et al., 2008). Future analyses are likely to use methods that include climate responses from different models (Huntingford et al., 2006; Gillett et al., 2005), but will rely on modelling centres creating appropriate simulations to explore the impact of $\mathrm{BC}$ or carbonaceous aerosols over the past decades. One of the tenets of detection and attribution is that climate response from models can be linearly combined. Whilst this may not an appropriate assumption for all circumstances (Ming and Ramaswamy, 2009), it has been demonstrated to be generally appropriate for detection and attribution purposes (Gillett et al., 2004). As models continue to become increasingly sophisticated with additional feedback processes included this assumption should be regularly tested. 

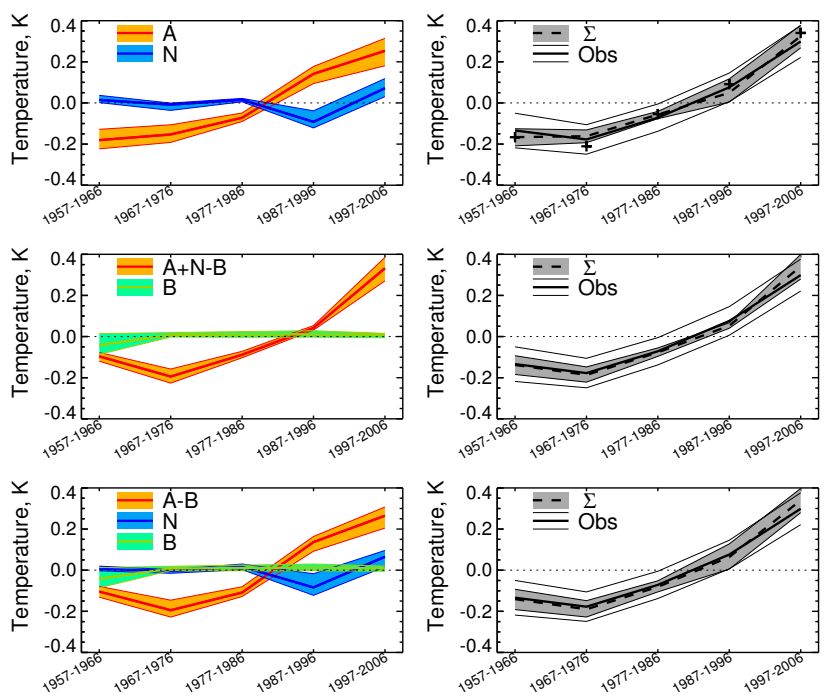

Fig. 13. Temperature reconstructions for 1957-2006 period, truncation=15. See Fig. 12.

Changes in observed surface radiative flux have been used to claim that anthropogenically produced aerosols have masked a larger than expected contribution to warming in global temperatures due to anthropogenic greenhouse gas emissions (Andreae et al., 2005). The so called effects of "solar dimming" and "solar brightening" (Norris and Wild, 2007; Ruckstuhl and Norris, 2009) have been associated with changes in aerosol concentrations leading to suggestions that reduced aerosol concentrations could be the largest contributor to warming over Europe seen over the last few decades (Philipona et al., 2009). However, caution is needed in this interpretation when changes in local surface radiative fluxes may not be associated with cooling/warming in the way expected, especially if absorbing aerosols like black carbon are present and when a regions temperature response can be dominated by forcing changes elsewhere (Shindell and Faluvegi, 2009; Stott and Jones, 2009).

With continuing greenhouse emissions from anthropogenic sources the IPCC assessed likely range limits for global climate to be warmer between 1.1-2.9 K (lower limits) to $2.4-6.4 \mathrm{~K}$ (upper limits), by the end of the 21 st century dependent on the economic scenario (IPCC, 2007). It has been suggested that controlling black carbon and associated carbonaceous aerosol emissions may assist in mitigating future climate change and indeed be more effective in the short term than focussing just on reducing greenhouse gas emissions (Hansen et al., 2007; Kopp and Mauzerall, 2010). Uncertainty in the indirect effects of carbonaceous aerosols makes quantifying the potential benefits of reducing BC emissions difficult. Together with how much other aerosols, that predominantly cool, are also controlled some studies suggesting that the overall effect could be to actually increase warming (Penner et al., 2003; Feichter et al.,
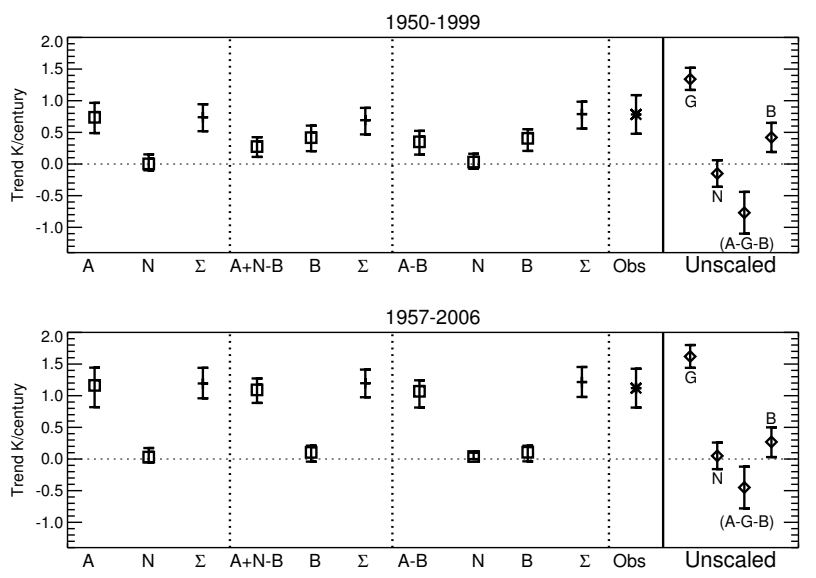

Fig. 14. Temperature reconstruction trends: $50 \mathrm{yr}$ analyses, truncation=15. Shown are trends K/century for each of the main regression reconstructions shown in Figs. 12 and 13 compared with the HadCRUT3v trend(Obs). On far right are trends of the unscaled reconstructions, i.e. no scaling factors applied, to enable comparison of the individual forcing factors with the attributable factors.

2003; Chen et al., 2010) or may cause an increase in $\mathrm{CO}_{2}$ emissions (Boucher and Reddy, 2008). The impact of BC on snow albedo in polar and glacier regions is a potentially strong reason for controlling emissions. Whilst the impact of BC on snow is likely to have limited influence globally (Shindell and Faluvegi, 2009), increased localised warming in such sensitive areas could have disproportionate impacts (Hansen and Nazarenko, 2004; Hansen et al., 2005, 2007; Flanner et al., 2007; Quinn et al., 2008; Ramanathan and Carmichael, 2008; Menon et al., 2010).

\section{Conclusions}

In this study we show that HadGEM1 broadly simulates observed near-surface temperature variations over the last $150 \mathrm{yr}$ reasonably well. Analysis of the simulated global mean temperatures suggest that warming from well mixed greenhouse gases, $1.06 \pm 0.07 \mathrm{~K} /$ century, would have been larger than the observed warming seen since $1900,0.73 \pm$ $0.08 \mathrm{~K} /$ century, if it were not for the partial cooling offset from aerosols, $-0.58 \pm 0.10 \mathrm{~K} /$ century, which supports the conclusions of IPCC (2007). The response to black carbon emissions from fossil fuels and biofuels was simulated to have significant warming over the 1900-2007 period, of $0.14 \pm 0.10 \mathrm{~K} /$ century and with increased warming over the last $50 \mathrm{yr}$ of the 20th century, $0.47 \pm 0.31 \mathrm{~K} /$ century. This warming is mostly seen over the Northern Hemisphere and is sufficiently different from the cooling from the other aerosols to be distinguishable. A detection and attribution analysis is able to detect the anthropogenic and natural influences on large spatial scales over the last $100 \mathrm{yr}$, but over the last $50 \mathrm{yr}$ or so is only able to robustly detect the dominant 
anthropogenic influence. $\mathrm{fBC}$ is detected with a warming contribution in the $1950-1999$ period of about $0.4 \mathrm{~K} /$ century, but not in the 1957-2006 period, possible due to fBC having a weaker influence in the later period. Whilst this is not a robust conclusive detection of fossil fuel and bio-fuel sources of black carbon, especially considering the discussed uncertainties, it is the first time that it has been detected separately from other aerosols.

Whilst controlling black carbon emissions in the future may provide some assistance in mitigating near future climate change, the overall influence is small compared to the much larger contribution from greenhouse gas emissions. In this study we did not include the influence of black carbon and/or soot on snow, which can potentially have a disproportionate influence on Arctic climate, so controls may be helpful there. However, any control on black carbon is likely to also influence other aerosol emissions, which could have the opposite effect to that intended by reducing the overall global cooling influence of all aerosols. Of course, control may be needed for other reasons, such as health and environmental concerns. The potential importance of black carbon influence on climate change, including a growing political awareness of the potential of its control as part of future mitigation policy (Kintisch, 2009), make understanding how much influence the different aerosols have on climate change an important and ongoing issue for study. However, the most effective way of reducing any long term warming in the climate remains reducing greenhouse gas emissions.

Acknowledgements. The authors would like to thank Andy Jones, Nicolas Bellouin, Jim Haywood and Olivier Boucher for discussions regarding setting up of the model experiments and how aerosols have evolved over the last century, Chris Durham, Jose Rodriguez and Tim Johns for their contribution in running the model control simulations. We are also grateful to Joshua Schwarz, Drew Shindell and the two anonymous referees for the useful comments on the original manuscript. This research was supported by the Joint DECC and Defra Integrated Climate Programme, DECC/Defra (GA01101)

Edited by: D. Shindell

\section{References}

Allen, M. R. and Stott, P. A.: Estimating signal amplitudes in optimal fingerprinting, part I: theory, Clim. Dynam., 21, 477-491, doi: 10.1007/s00382-003-0313-9, 2003.

Andreae, M. O., Jones, C. D., and Cox, P. M.: Strong present-day aerosol cooling implies a hot future, Nature, 435, 1187-1190, 2005.

Barnett, T. P., Hegerl, G. C., Santer, B., and Taylor, K.: The potential effect of GCM uncertainties and internal atmospheric variability on anthropogenic signal detection, J. Climate, 11, 659675, 1998.

Bellouin, N., Boucher, O., Haywood, J., Johnson, C., Jones, A., Rae, J., and Woodward, S.: Improved representation of aerosols for HadGEM2, Tech. Rep. HCTN 73, Hadley Centre, Met Office, available at: http://www.metoffice.gov.uk/publications/HCTN/, 2007.

Bellouin, N., Jones, A., Haywood, J., and Christopher, S. A.: Updated estimate of aerosol direct radiative forcing from satellite observations and comparison against the Hadley Centre climate model, J. Geophys. Res., 113, D10205, doi:10.1029/2007JD009385, 2008.

Bodas-Salcedo, A., Ringer, M. A., and Jones, A.: Evaluation of the Surface Radiation Budget in the Atmospheric Component of the Hadley Centre Global Environmental Model (HadGEM1), J. Climate, 21, 4723-4748, 2008.

Bond, T. C., Bhardwaj, E., Dong, R., Jogani, R., Jung, S., Roden, C., Streets, D. G., and Trautmann, N. M.: Historical emissions of black and organic carbon aerosol from energyrelated combustion, Global Biogeochem. Cy., 21, GB2018, doi:10.1029/2006GB002840, 2007.

Boucher, O. and Reddy, M. S.: Climate trade-off between black carbon and carbon dioxide emissions, Energy Policy, 36, 193200, 2008.

Brohan, P., Kennedy, J. J., Haris, I., Tett, S. F. B., and Jones, P. D.: Uncertainty estimates in regional and global observed temperature changes: a new dataset from 1850, J. Geophys. Res., 111, D12106, doi:10.1029/2005JD006548, 2006.

Chen, W.-T., Lee, Y. H., Adams, P. J., Nenes, A., and Seinfeld, J. H.: Will black carbon mitigation dampen aerosol indirect forcing?, Geophys. Res. Lett., 37, L09801, doi:10.1029/2010GL042886, 2010.

Chung, S. H. and Seinfeld, J. H.: Climate response of direct radiative forcing of anthropogenic black carbon, J. Geophys. Res., 110, D11102, doi:10.1029/2004JD005441, 2005.

Church, J. A., White, N. J., and Arblaster, J. M.: Significant decadal-scale impact of volcanic eruptions on sea level and ocean heat content, Nature, 438, 74-77, doi:10.1038/nature04237, 2005.

Easterling, D. R. and Wehner, M. F.: Is the climate warming or cooling?, Geophys. Res. Lett., 36, L08706, doi:10.1029/2009GL037810, 2009.

Feichter, J., Sausen, R., Graß1, H., and Fiebig, M.: Comment on "Control of fossil-fuel particulate black carbon and organic matter possibly the most effective method of slowing global warming”, J. Geophys. Res., 108, 4767, doi:10.1029/2002JD003223, 2003.

Flanner, M. G., Zender, C. S., Randerson, J. T., and Rasch, P. J.: Present-day climate forcing and response from black carbon in snow, J. Geophys. Res., 112, D11202, doi:10.1029/2006JD008003, 2007.

Forster, P. M. D. and Taylor, K. E.: Climate Forcings and Climate Sensitivities Diagnosed from Coupled Climate Model Integrations, J. Climate, 19, 6181-6194, 2006.

Forster, P., Ramaswamy, V., Artaxo, P., Berntsen, T., Betts, R., Fahey, D. W., Haywood, J., Lean, J., Lowe, D. C., Myhre, G., Nganga, J., Prinn, R., Raga, G., Schulz, M., and Van Dorland, R.: Changes in Atmospheric Constituents and in Radiative Forcing, in: Climate Change 2007: The Physical Science Basis. Contribution of Working Group I to the Fourth Assessment Report of the Intergovernmental Panel on Climate, edited by: Solomon, S., Qin, D., Manning, M., Chen, Z., Marquis, M., Averyt, K. B., Tignor, M., and Miller, H. L., Cambridge University Press, 2007. Gillett, N. P., Wehner, M. F., Tett, S. F. B., and Weaver, A. J.: Test- 
ing the linearity of the response to combined greenhouse gas and sulfate aerosol forcing, Geophys. Res. Lett., 31, L13201, doi:10.1029/2004GL020111, 2004.

Gillett, N., Allan, R., and Ansell, T.: Detection of external influence on sea level pressure with a multi-model ensemble, Geophys. Res. Lett., 32, L19714, doi:10.1029/2005GL023640, 2005.

Gleckler, P. J., AchutaRao, K., Gregory, J. M., Santer, B. D., Taylor, K. E., and Wigley, T. M. L.: Krakatoa lives: The effect of volcanic eruptions on ocean heat content and thermal expansion, Geophys. Res. Lett., 33, L17702, doi:10.1029/2006GL026771, 2006.

Gregory, J. M., Ingram, W. J., Palmer, M. A., Jones, G. S., Stott, P. A., Thorpe, R. B., Lowe, J. A., Johns, T. C., and Williams, K. D.: A new method for diagnosing radiative forcing and climate sensitivity, Geophys. Res. Lett., 31, L03205, doi:10.1029/2003g1018,747, 2004.

Hansen, J. and Nazarenko, L.: Soot climate forcing via snow and ice albedos, P. Natl. Acad. Sci. USA, 101, 423-428, doi:10.1073/pnas.2237157100, 2004.

Hansen, J., Sato, M., Ruedy, R., Nazarenko, L., Lacis, A., Schmidt, G. A., Russell, G., Aleinov, I., Bauer, M., Bauer, S., Bell, N., Cairns, B., Canuto, V., Chandler, M., Cheng, Y., Del Genio, A., Faluvegi, G., Fleming, E., Friend, A., Hall, T., Jackman, C., Kelley, M., Kiang, N., Koch, D., Lean, J., Lerner, J., Lo, K., Menon, S., Miller, R. L., Minnis, P., Novakov, T., Oinas, V., Perlwitz, J., Perlwitz, J., Rind, D., Romanou, A., Shindell, D., Stone, P., Sun, S., Tausnev, N., Thresher, D., Wielicki, B., Wong, T., Yao, M., and Zhang, S.: Efficacy of climate forcings, J. Geophys. Res., 110, D18104,doi:10.1029/2005JD005776, 2005.

Hansen, J., Sato, M., Kharecha, P., Russell, G., Lea, D. W., and Siddall, M.: Climate change and trace gases, Philos. T. Roy. Soc. A, 365, 1925-1954, 2007.

Hasselmann, K.: Multi-pattern fingerprint method for detection and attribution of climate change, Clim. Dynam., 13, 601-612, 1997.

Haywood, J. and Schulz, M.: Causes of the reduction in uncertainty in the anthropogenic radiative forcing of climate between IPCC (2001) and IPCC (2007), Geophys. Res. Lett., 34, L20701, doi:10.1029/2007GL030749, 2007.

Hegerl, G. C., von Storch, H., Hasselmann, K., Santer, B. D., Cubasch, U., and Jones, P. D.: Detecting Greenhouse Gas induced Climate Change with an Optimal Fingerprint Method, J. Climate, 9, 2281-2306, 1996.

Hegerl, G. C., Zwiers, F. W., Braconnot, P., Gillett, N. P., Luo, Y., Marengo Orsini, J. A., Nicholls, N., Penner, J. E., and Stott, P. A.: Understanding and Attributing Climate Change, in: Climate Change 2007: The Physical Science Basis. Contribution of Working Group I to the Fourth Assessment Report of the Intergovernmental Panel on Climate Change, edited by: Solomon, S., Qin, D., Manning, M., Chen, Z., Marquis, M., Averyt, K. B., Tignor, M., and Miller, H. L., Cambridge University Press, 2007.

Huntingford, C., Stott, P. A., Allen, M. R., and Lambert, F. H.: Incorporating model uncertainty into attribution of observed temperature change, Geophys. Res. Lett., 33, L05710, doi:10.1029/2005GL0248312, 2006.

IDAG (The International Ad Hoc Detection and Attribution Group): Detecting and Attributing External Influences on the Climate System: A Review of Recent Advances, J. Climate, 18, 12911314, 2005.

IPCC: Summary for Policymakers, in: Climate Change 2007: The
Physical Science Basis. Contribution of Working Group I to the Fourth Assessment Report of the Intergovernmental Panel on Climate Change, edited by Solomon, S., Qin, D., Manning, M., Chen, Z., Marquis, M., Averyt, K. B., Tignor, M., and Miller, H. L., Cambridge University Press, 2007.

Johns, T. C., Durman, C. F., Banks, H. T., Roberts, M. J., McLaren, A., Ridley, J. K., Senior, C. A., Williams, K. D., Jones, A., Rickard, G. J., Cusack, S., Ingram, W. J., Sexton, D. M. H., Joshi1, M. M., Dong, B.-W., Spencer, H., Hill, R. S. R., Gregory, J. M., Keen, A. B., Pardaens, A. K., Lowe, J. A., BodasSalcedo, A., Stark, S., and Searl, Y.: The new Hadley Centre climate model HadGEM1: Evaluation of coupled simulations in comparison to previous models, J. Climate, 19, 1327-1353, 2006.

Jones, A., Roberts, D. L., Woodage, M. J., and Johnson, C. E.: Indirect sulphate aerosol forcing in a climate model with an interactive sulphur cycle, J. Geophys. Res., 106, 293-320, 2001.

Jones, A., Haywood, J. M., and Boucher, O.: Aerosol forcing, climate response and climate sensitivity in the Hadley Centre climate model, J. Geophys. Res., 112, D20211, doi:10.1029/2007JD008688, 2007.

Jones, G. S., Gregory, J. M., Stott, P. A., Tett, S. F. B., and Thorpe, R. B.: An AOGCM simulation of the climate response to a volcanic super-eruption, Clim. Dynam., 25, 725-738, doi:10.1007/s00382-005-0066-8, 2005a.

Jones, G. S., Jones, A., Roberts, D. L., Stott, P. A., and Williams, K. D.: Sensitivity of global scale attribution results to inclusion of climatic response to black carbon, Geophys. Res. Lett., 32, L14701, doi:10.1029/2005GL023370, 2005b.

Jones, G. S., Stott, P. A., and Christidis, N.: Human contribution to rapidly increasing frequency of very warm Northern Hemisphere summers, J. Geophys. Res., 113, D02109, doi:10.1029/2007JD008914, 2008.

Joshi, M. M. and Jones, G. S.: The climatic effects of the direct injection of water vapour into the stratosphere by large volcanic eruptions, Atmos. Chem. Phys., 9, 6109-6118, doi:10.5194/acp9-6109-2009, 2009.

Kintisch, E.: New Push Focuses on Quick Ways to Curb Global Warming, Science, 324, p. 323, 2009.

Knight, J., Kennedy, J. J., Folland, C., Harris, G., Jones, G. S., Palmer, M., Parker, D., Scaife, A., and Stott, P.: Do global temperature trends over the last decade falsify climate predictions?, B. Am. Meteorol. Soc., 90, 522-523, 2009.

Koch, D. and Del Genio, A. D.: Black carbon semi-direct effects on cloud cover: review and synthesis, Atmos. Chem. Phys., 10, 7685-7696, doi:10.5194/acp-10-7685-2010, 2010.

Koch, D., Menon, S., Del Genio, A., Ruedy, R., Alienov, I., and Schmidt, G. A.: Distinguishing Aerosol Impacts on Climate over the Past Century, J. Clim., 22, 2659-2677, 2009a.

Koch, D., Schulz, M., Kinne, S., McNaughton, C., Spackman, J. R., Balkanski, Y., Bauer, S., Berntsen, T., Bond, T. C., Boucher, O., Chin, M., Clarke, A., De Luca, N., Dentener, F., Diehl, T., Dubovik, O., Easter, R., Fahey, D. W., Feichter, J., Fillmore, D., Freitag, S., Ghan, S., Ginoux, P., Gong, S., Horowitz, L., Iversen, T., Kirkevåg, A., Klimont, Z., Kondo, Y., Krol, M., Liu, X., Miller, R., Montanaro, V., Moteki, N., Myhre, G., Penner, J. E., Perlwitz, J., Pitari, G., Reddy, S., Sahu, L., Sakamoto, H., Schuster, G., Schwarz, J. P., Seland, Ø., Stier, P., Takegawa, N., Takemura, T., Textor, C., van Aardenne, J. A., and Zhao, Y.: Evalu- 
ation of black carbon estimations in global aerosol models, Atmos. Chem. Phys., 9, 9001-9026, doi:10.5194/acp-9-9001-2009, 2009b.

Kopp, R. E. and Mauzerall, D. L.: Assessing the climatic benefits of black carbon mitigation, P. Natl. Acad. Sci. USA, 107, 1170311708, doi:10.1073/pnas.0909605107, 2010.

Lamarque, J.-F., Bond, T. C., Eyring, V., Granier, C., Heil, A., Klimont, Z., Lee, D., Liousse, C., Mieville, A., Owen, B., Schultz, M. G., Shindell, D., Smith, S. J., Stehfest, E., Van Aardenne, J., Cooper, O. R., Kainuma, M., Mahowald, N., McConnell, J. R., Naik, V., Riahi, K., and van Vuuren, D. P.: Historical (1850-2000) gridded anthropogenic and biomass burning emissions of reactive gases and aerosols: methodology and application, Atmos. Chem. Phys., 10, 7017-7039, doi:10.5194/acp10-7017-2010, 2010.

Lean, J. L. and Rind, D. H.: How will Earth's surface temperature change in future decades?, Geophys. Res. Lett., 36, L15708, doi:10.1029/2009GL038932, 2009.

Martin, G. M., Ringer, M. A., Pope, V. D., Jones, A., Dearden, C., and Hinton, T. J.: The Physical Properties of the Atmosphere in the New Hadley Centre Global Environmental Model (HadGEM1). Part I: Model Description and Global Climatology, J. Climate, 19, 1274-1301, 2006.

Meehl, G. A., Stocker, T. F., Collins, W. D., Friedlingstein, P., Gaye, A. T., Gregory, J. M., Kitoh, A., Knutti, R., Murphy, J. M., Noda, A., Raper, S. C. B., Watterson, I. G., Weaver, A. J., and Zhao, Z. C.: Global Climate Projections, in: Climate Change 2007: The Physical Science Basis. Contribution of Working Group I to the Fourth Assessment Report of the Intergovernmental Panel on Climate Change, edited by: Solomon, S., Qin, D., Manning, M., Chen, Z., Marquis, M., Averyt, K. B., Tignor, M., and Miller, H. L., Cambridge University Press, 2007.

Meehl, G. A., Arblaster, J. M., and Collins, W. D.: Effects of black carbon aerosols on the Indian monsoon, J. Climate, 21, 28692882, 2008.

Menon, S., Koch, D., Beig, G., Sahu, S., Fasullo, J., and Orlikowski, D.: Black carbon aerosols and the third polar ice cap, Atmos. Chem. Phys., 10, 4559-4571, doi:10.5194/acp-10-4559-2010, 2010.

Ming, Y. and Ramaswamy, V.: Nonlinear climate and hydrological responses to aerosol effects, J. Climate, 22, 1329-1339, 2009.

Murphy, D. M., Solomon, S., Portmann, R. W., Rosenlof, K. H., Forster, P. M., and Wong, T.: An observationally based energy balance for the Earth since 1950, J. Geophys. Res., 114, D17107, doi:10.1029/2009JD012105, 2009.

Myhre, G.: Consistency Between Satellite-Derived and Modeled Estimates of the Direct Aerosol Effect, Science, 325, 187-190, 2009.

Nagashima, T., Shiogama, H., Yokohata, T., Takemura, T., Crooks, S. A., and Nozawa, T.: Effect of carbonaceous aerosols on surface temperature in the mid twentieth century, Geophys. Res. Lett., 33, L04702, doi:10.1029/2005GL024887, 2006.

Norris, J. R. and Wild, M.: Trends in aerosol radiative effects over Europe inferred from observed cloud cover, solar "dimming" and solar "brightening", J. Geophys. Res., 112, D08214, doi:10.1029/2006JD007794, 2007.

Novakov, T., Ramanathan, V., Hansen, J. E., Kirchstetter, T. W., Sato, M., Sinton, J. E., and Sathaye, J. A.: Large Historical changes of fossil-fuel black carbon aerosols, Geophys. Res. Lett.,
30, 57-1-57-4, doi:10.1029/2002GL016345, 2003.

Ohara, T., Akimoto, H., Kurokawa, J., Horii, N., Yamaji, K., Yan, X., and Hayasaka, T.: An Asian emission inventory of anthropogenic emission sources for the period 1980-2020, Atmos. Chem. Phys., 7, 4419-4444, doi:10.5194/acp-7-4419-2007, 2007.

Penner, J. E., Zhang, S. Y., and Chuang, C. C.: Soot and smoke aerosol may not warm climate, J. Geophys. Res., 108, 4657, doi:10.1029/2003JD003409, 2003.

Philipona, R., Behrens, K., and Ruckstuhl, C.: How declining aerosols and rising greenhouse gases forced rapid warming in Europe since the 1980s, Geophys. Res. Lett., 36, L02806, doi:10.1029/2008GL036350, 2009.

Pope, V., Brown, S., Clark, R., Collins, M., Collins, W., Dearden, C., Gunson, J., Harris, G., Jones, C., Keen, A., Lowe, J., Ringer, M., Senior, C., Sitch, S., Webb, M., and Woodward, S.: The Met Office Hadley Centre climate modelling capability: the competing requirements for improved resolution, complexity and dealing with uncertainty, Philos. T. Roy. Soc. A, 365, 2635-2657, 2007.

Press, W. H., Teukolsky, S. A., Vetterling, W. T., and Flannery, B. P.: Numerical Recipes in Fortran: the Art of Scientific Computing, Cambridge University Press, Cambridge, UK, 2nd edn., 963 pp., 1992.

Quinn, P. K., Bates, T. S., Baum, E., Doubleday, N., Fiore, A. M., Flanner, M., Fridlind, A., Garrett, T. J., Koch, D., Menon, S., Shindell, D., Stohl, A., and Warren, S. G.: Short-lived pollutants in the Arctic: their climate impact and possible mitigation strategies, Atmos. Chem. Phys., 8, 1723-1735, doi:10.5194/acp8-1723-2008, 2008.

Rahmstorf, S., Cazenave, A., Church, J. A., Hansen, J. E., Keeling, R. F., Parker, D. E., and Somerville, R. C. J.: Recent climate observations compared to projections, Science, 316, 709-709, 2007.

Ramanathan, V. and Carmichael, G.: Global and regional climate changes due to black carbon, Nat. Geosci., 1, 221-227, 2008.

Ramanathan, V., Chung, C., Kim, D., Bettge, T., Buja, L., Kiehl, J. T., Washington, W. M., Fu, Q., Sikka, D. R., and Wild, M.: Atmospheric brown clouds: Impacts on South Asian climate and hydrological cycle, P. Natl. Acad. Sci. USA, 102, 5327-5333, 2005.

Ramanathan, V., Ramana, M. V., Roberts, G., Kim, D., Corrigan, C., Chung, C., and Winker, D.: Warming trends in Asia amplified by brown cloud solar absorption, Nature, 448, 575-578, 2007.

Randall, D. A., Wood, R. A., Bony, S., Colman, R., Fichefet, T., Fyfe, J., Kattsov, V., Pitman, A., Shukla, J., Srinivasan, J., Stouffer, R. J., Sumi, A., and Taylor, K. E.: Climate Models and Their Evaluation, in: Climate Change 2007: The Physical Science Basis. Contribution of Working Group I to the Fourth Assessment Report of the Intergovernmental Panel on Climate Change, edited by: Solomon, S., Qin, D., Manning, M., Chen, Z., Marquis, M., Averyt, K. B., Tignor, M., and Miller, H. L., Cambridge University Press, 2007.

Ringer, M. A., Martin, G. M., Greeves, C. Z., Hinton, T. J., James, P. M., Pope, V. D., Scaife, A. A., and Stratton, R. A.: The Physical Properties of the Atmosphere in the New Hadley Centre Global Environmental Model (HadGEM1). Part II: Aspects of variability and regional climate, J. Climate, 19, 1302-1326, 2006. 
Roberts, D. L. and Jones, A.: Climate sensitivity to black carbon aerosol from fossil fuel combustion, J. Geophys. Res., 109, D16202, doi:10.1029/2004JD004676, 2004.

Roeckner, E., Stier, P., Feichter, J., Kloster, S., Esch, M., and Fischer-Bruns, I.: Impact of carbonaceous aerosol emissions on regional climate change, Clim. Dynam., 27, 553-571, 2006.

Ruckstuhl, C. and Norris, J. R.: How do aerosol histories affect solar "dimming" and "brightening" over Europe?: IPCC-AR4 models versus observations, J. Geophys. Res., 114, D00D04, doi:10.1029/2008JD011066, 2009.

Sato, M., Hansen, J. E., McCormick, M. P., and Pollack, J. B.: Stratospheric aerosol optical depths (1850-1990), J. Geophys. Res., 98, 22987-22994, 1993.

Schulz, M., Textor, C., Kinne, S., Balkanski, Y., Bauer, S., Berntsen, T., Berglen, T., Boucher, O., Dentener, F., Guibert, S., Isaksen, I. S. A., Iversen, T., Koch, D., Kirkevåg, A., Liu, X., Montanaro, V., Myhre, G., Penner, J. E., Pitari, G., Reddy, S., Seland, Ø., Stier, P., and Takemura, T.: Radiative forcing by aerosols as derived from the AeroCom present-day and pre-industrial simulations, Atmos. Chem. Phys., 6, 5225-5246, doi:10.5194/acp-6-5225-2006, 2006.

Shindell, D. and Faluvegi, G.: Climate response to regional radiative forcing during the twentieth century, Nat. Geosci., 2, 294 $300,2009$.

Shindell, D., Lamarque, J.-F., Unger, N., Koch, D., Faluvegi, G., Bauer, S., Ammann, M., Cofala, J., and Teich, H.: Climate forcing and air quality change due to regional emissions reductions by economic sector, Atmos. Chem. Phys., 8, 7101-7113, doi:10.5194/acp-8-7101-2008, 2008.

Smith, D. M., Cusack, S., Colman, A. W., Folland, C. K., Harris, G. R., and Murphy, J. M.: Improved surface temperature prediction for the coming decade from a global climate model, Science, 317, 796-799, 2007.

Smith, S. J., van Aardenne, J., Klimont, Z., Andres, R., Volke, A., and Delgado Arias, S.: Anthropogenic sulfur dioxide emissions: 18502005, Atmos. Chem. Phys. Discuss., 10, 1611116151, doi:10.5194/acpd-10-16111-2010, 2010.

Solomon, S., Rosenlof, K. H., Portmann, R. W., Daniel, J. S., Davis, S. M., Sanford, T. J., and Plattner, G.-K.: Contributions of Stratospheric Water Vapor to Decadal Changes in the Rate of Global Warming, Science, 327, 1219-1223, 2010.

Stenchikov, G., Delworth, T. L., Ramaswamy, V., Stouffer, R. J., Wittenberg, A., and Zeng, F.: Volcanic signals in oceans, J. Geophys. Res., 114, D16104, doi:10.1029/2008JD011673, 2009.

Stott, P. A. and Jones, G. S.: Variability of high latitude amplification of anthropogenic warming, Geophys. Res. Lett., 36, L10701, doi:10.1029/2009GL037698, 2009.

Stott, P. A., Tett, S. F. B., Jones, G. S., Allen, M. R., Mitchell, J. F. B., and Jenkins, G. J.: External Control of 20th Century Temperature by Natural and Anthropogenic Forcing, Science, 290, 2133-2137, 2000.

Stott, P. A., Allen, M. R., and Jones, G. S.: Estimating signal amplitudes in optimal fingerprinting, part II: application to general circulation models, Clim. Dynam., 21, 493-500, doi:10.1007/s00382-003-0314-8, 2003a.

Stott, P. A., Jones, G. S., and Mitchell, J. F. B.: Do models underestimate the solar contribution to recent climate change?, J. Climate, 16, 4079-4093, 2003b.

Stott, P. A., Jones, G. S., Lowe, J. A., Thorne, P., Durman, C., Johns,
T. C., and Thelen, J.-C.: Transient climate simulations with the HadGEM1 climate model : causes of past warming and future climate change, J. Climate, 19, 2763-2782, 2006a.

Stott, P. A., Mitchell, J. F. B., Allen, M. R., Delworth, T. L., Gregory, J. M., Meehl, G. A., and Santer, B. D.: Observational constraints on past attributable warming and predictions of future global warming, J. Climate, 19, 3055-3069, 2006 b.

Stott, P. A., Gillett, N. P., Hegerl, G. C., Karoly, D. J., Stone, D. A., Zhang, X., and Zwiers, F.: Detection and attribution of climate change: a regional perspective, Wiley Interdisciplinary Reviews: Climate Change, 1, 192-211, 2010.

Takemura, T., Nozawa, T., Emori, S., Nakajima, T. Y., and Nakajima, T.: Simulation of climate response to aerosol direct and indirect effects with aerosol transport-radiation model, J. Geophys. Res., 110, D02202, doi:10.1029/2004JD005029, 2005.

Takemura, T., Tsushima, Y., Yokohata, T., Nozawa, T., Nagashima, T., and Nakajima, T.: Time evolutions of various radiative forcings for the past 150 years estimated by a general circulation model, Geophys. Res. Lett., 33, L19705, doi:10.1029/2006GL026666, 2006.

Tett, S. F. B., Jones, G. S., Stott, P. A., Hill, D. C., Mitchell, J. F. B., Allen, M. R., Ingram, W. J., Johns, T. C., Johnson, C. E., Jones, A., Roberts, D. L., Sexton, D. M. H., and Woodage, M. J.: Estimation of natural and anthropogenic contributions to $20^{\text {th }}$ Century temperature change, J. Geophys. Res., 107, 10-24, doi:10.1029/2000JD000028, 2002.

Thomason, L. W., Burton, S. P., Luo, B.-P., and Peter, T.: SAGE II measurements of stratospheric aerosol properties at non-volcanic levels, Atmos. Chem. Phys., 8, 983-995, doi:10.5194/acp-8-9832008, 2008.

Trenberth, K. E. and Fasullo, J. T.: Climate Change: Tracking Earth's Energy, Science, 328, 316-317, 2010.

Trenberth, K. E., Jones, P. D., Ambenje, P., Bojariu, R., Easterling, D., Klein Tank, A., Parker, D., Rahimzadeh, F., Renwick, J. A., Rusticucci, M., Soden, B., and Zhai, P.: Observations: Surface and Atmospheric Climate Change, in: Climate Change 2007: The Physical Science Basis. Contribution of Working Group I to the Fourth Assessment Report of the Intergovernmental Panel on Climate Change, edited by: Solomon, S., Qin, D., Manning, M., Chen, Z., Marquis, M., Averyt, K. B., Tignor, M., and Miller, H. L., Cambridge University Press, 2007.

Wallack, J. S. and Ramanathan, V.: The Other Climate Changers: Why Black Carbon and Ozone Also Matter, Foreign Aff., 88, 105-113, 2009.

Wang, C.: The sensitivity of tropical convective precipitation to the direct radiative forcings of black carbon aerosols emitted from major regions, Ann. Geophys., 27, 3705-3711, doi:10.5194/angeo-27-3705-2009, 2009.

Wang, K., Dickinson, R. E., and Liang, S.: Clear Sky Visibility Has Decreased over Land Globally from 1973 to 2007, Science, 323, 1468-1470, 2009.

Woodage, M., Davison, P., and Roberts, D. L.: Aerosol processes. Unified Model Documentation Paper 20, Tech. Rep. HCTN, Hadley Centre, Met Office, Exeter, UK, 2003.

Xu, B. Q., Cao, J. J., Hansen, J., Yao, T. D., Joswia, D. R., Wang, N. L., Wu, G. J., Wang, M., Zhao, H. B., Yang, W., Liu, X. Q., and He, J.: Black soot and the survival of Tibetan glaciers, P. Natl. Acad. Sci. USA, 106, 22114-22118, 2009. 